\title{
DEL VSVS MERCATORVM AL USO DE COMERCIO. NOTAS Y TEXTOS SOBRE LA COSTUMBRE MERCANTIL
}

FROM VSVS MERCATORVM TO COMMERCIAL USE. NOTES AND TEXTS ON TRADE MORES

Carlos Petit

Universidad Onubense

RESUMO: A cultura mercantil, nos tempos medievais, era um fenômeno complexo que não se restringia às limitações modernas decorrentes da codificação. As práticas mercantis não se limitavam ao direito comercial legislado com normas abstratas, mas se expressavam nos costumes de profissionais e de membros de corporações em suas atividades diárias. Esses costumes eram direitos originados da prática e, mais do que normas jurídicas autônomas, eram fontes primárias para a produção do direito. Essas normas costumeiras eram, sobretudo, o direito dos comerciantes e estabeleciam parâmetros de conduta profissional e de intercâmbio de mercadorias. As práticas comerciais possuíam ampla expressão da tradição do ius commune com um forte caráter religioso e cooperativo fundado no valor da amizade.

PALAVRAS-CHAVE: cultura mercantil; common law; práticas comerciais medievais.
ABSTRACT: Mercantile culture in medieval times was a complex phenomenon not restricted to modern limitations due to the process of codification. Mercantile practices did not limit themselves to legislated trade law on the basis of abstract rules but they manifest themselves through the habits of corporation's members and professionals. Such habits were rights derived from their practices and more than autonomous legal rules they were primary sources for law making. These common law rules were the law of merchants and they determined standards for professional behavior and commodities trade. Commercial or trade practices expressed the tradition of ius commune with a strong religious and cooperative feature based on the value of friendship.

KEYWORDS: mercantile culture; common law; medieval commercial practices.

\footnotetext{
* Professor Catedrático da Universidade Huelva,
} Espanha. 
Mercatorum actibus consuetudo attenditur...

"No hay en Cadiz como en Londres un formal establecimiento de bolsa de comercio", advertía un experto del comercio que vivió en la España ilustrada". "La calle nueva y plazuela de San Agustin, sitios de gran concurrencia de Comerciantes, suplen y sirven de tales: pero ni todos freqüentan aquellos parages, ni pued[e] haber la franqueza en las noticias de los negocios, que tal vez aprovecha á su propagacion. Corren las especies: se habla de tal ó tal negociación, de tal ó tal letra á cargo de una ú otra casa, se suscita tal ó tal duda, y no se apuran ni el asunto, ni las dificultades. Esto se consigue en los combites, no siendo extraño el que durante el tiempo de tomar una taza de café se haga una gran negociacion, se repare el crédito del librador de una letra, saliendo quien por su honor la pague ó se dirima una duda, cuya purificación costaria un pleyto". Nada se expresa aquí sobre la costumbre o los usos del comercio, y sin embargo difícilmente podría presentar a mis lectores un texto que mejor introdujera el argumento que los amigos de Salamanca me han asignado.

En una primera aproximación, Juan Antonio de los Heros - autor del párrafo anterior $^{2}$ - explicaba llanamente el estilo de

1 Juan Antonio de los Heros Fernández, Discursos sobre el comercio, ed. Banco Bilbao Vizcaya, pról. de José Manuel de Barrenechea, [Madrid, Espasa-Calpe], 1989. La obra, compuesta hacia 1770 , fue publicada tardíamente por Antonio de Valladares (cf. Semanario Erudito, tomos XXVI y XXVII, 1790); para la cita recogida, cf. tomo XXVII, p. 179.

2 Para la intervención del sobrino Juan Francisco, jurista de formación, en una disertación al fin y al cabo póstuma, cf. Barrenechea cit. (n. 1), pp. xxx ss, pero no hay dudas de que los pasajes alegados pertenecen al tío Juan Antonio, autor principal. la plaza de Cádiz al cerrar negocios, sin disponerse allí de bolsa de comercio. A falta de tal institución, las noticias del giro, la información sobre el tráfico de letras, las dudas sobre la solvencia y el honor de un colega... podían circular y resolverse mientras se celebraba un banquete o en una reunión de café, lo que hacía muy útil y aun rentable el dinero consumido - esos "diez ó doce mil pesos que una casa famosa de Comercio... expende cada año en la mesa, criados, diversiones, \&c." (ibd.p. 178) - en semejantes ocasiones de convivencia festiva; pues sabemos que "en un combite ó concurrencia se concilian los animos: y si ofrece la casualidad alguna duda sobre letra de cambio, pendiente entre los mismos concurrentes, la dirimen los otros amistosamente. Si se refiere la letra protestada, suele haber mas proporcion de que alguno la satisfaga por honor ó del librador, ó de los endosantes, ó del aceptante" (p. 179).

Dejemos un momento a De los Heros para observar que esos gastos suntuarios, lo mismo que la aceptación graciosa de letras para salvar el honor de algún colega del comercio algo al parecer tan frecuente en los cafés gaditanos - constituyen los índices o espías de una cultura mercantil diversa, cuyas dichas 'costumbres' - sean cuales fueran y tuviesen el alcance y contenido jurídico que se quiera - nos conviene contextualizar.

Un contexto, que muy a duras penas trazaremos sirviéndonos de la consulta de los libros de derecho. En efecto, a pesar de reflexiones ejemplares - me permito mencionar a mi admirado Edouard Lambert - la experiencia del derecho codificado, el llamado acertadamente "paradigma lógicopositivista" (Pietro Costa) del hombre de 
leyes contemporáneo ha hecho que no tomemos demasiado en serio el mundo de los usos y costumbres como vías eficaces de creación y expresión de la norma jurídica.

Además, sería equivocado agotar la costumbre en el derecho consuetudinario, una segunda limitación del experto moderno que viene lastrando la elaboración especializada de los historiadores ${ }^{3}$. También para los estudiosos del pasado la costumbre suele quedar reducida a la condición de fuente secundaria, de particularidad 'del lugar' o pintoresquismo foral... tan entrañable como en sustancia irrelevante; en las exposiciones de conjunto sólo obtiene algún protagonismo en referencia a los tiempos medievales, aunque ni siquiera entonces la alusión a usos más o menos normativos otorga el debido relieve a la vocación constitucional que encerraría el concepto, esto es, la costumbre como una manifestación - cuando no, francamente, una auténtica reivindicación de libertades y autonomía a favor de los miembros de una profesión, los agregados en un ente corporativo o los pobladores de un núcleo rural. Al menos, sabemos ahora que los primeros estudiosos de la costumbre antropólogos, anticuarios, cronistas - fueron

3 Para lo que sigue, vid.E.P. Thompson, Costumbres en común (1991), trad. Jordi Beltrán - Eva Rodríguez, revisión de Elena Grau, Barcelona, Crítica, 1995, particularmente la introducción sobre "Costumbre y cultura", pp. 13 ss. Sobre una de las vertientes jurídicas de la cuestión, António M. Hespanha, "Sabios y rústicos. La dulce violencia de la razón jurídica" (1983), ahora en La gracia del Derecho. Economía de la cultura en la edad moderna, Madrid, Centro de Estudios Constitucionales, 1993, 17-60; el mismo Autor ha prestado atención a formas jurídicas y políticas nooficiales: vid. Vísperas del Leviatán. Instituciones y poder político (Portugal, siglo XVII), trad. Fernando Bouza, Madrid, Taurus, 1989, pp. 363 ss. responsables directos de la extinción de una auténtica mentalidad tradicional y plural al reducir a cuestión de folklore y de hábitos populares (sc. plebeyos, rústicos, primitivos... así des-calificados desde la superioridad implícita en el mismo ejercicio de observación folklorista) cuanto venía siendo desde hacía siglos sencillamente una cultura diversa. Y es que, en realidad, "las costumbres hacen cosas: no son formulaciones abstractas de significados, ni búsquedas de los mismos, aunque pueden transmitir significados. Las costumbres están claramente conectadas y enraizadas en las realidades materiales y sociales de la vida y el trabajo, aunque no son sencillamente derivados de dichas realidades ni reexpresiones de las mismas. Las costumbres pueden proporcionar un contexto en el cual las personas pueden hacer cosas que serían más difíciles de hacer directamente... pueden conservar la necesidad de acción colectiva, ajuste colectivo de intereses, y expresión colectiva de sentimientos y emociones dentro del terreno y el dominio de los coparticipantes en una costumbre, haciendo las veces de frontera que excluye a los intrusos"4.

Considero que la anterior descripción digámoslo con una palabra: costumbre equivalente a cultura - no sólo encierra la ventaja de integrar conocimientos procedentes de varios campos del saber; permite además enfocar el universo de las prácticas y conductas de los antiguos mercaderes con la complejidad que aquí nos interesa.

Que la costumbre mercantil fuera algo más que un autónomo derecho del comercio, que detrás de un banquete barroco podía

4 Texto de Gerald M. Sider (1986) en Thompson cit. (n. 3), p. 26. 
esconderse otra cosa que el ánimo liberal de la donación o el despilfarro 'traidor' de una burguesía con aspiraciones nobiliarias, lo indicaría, con su rotundo testimonio negativo, la jurisprudencia de ancien régime; como se sabe, cuando los letrados trataron específicamente del derecho consuetudinario casi nunca prestaron atención a las costumbres de los mercaderes ${ }^{5}$. Por supuesto, tales costumbres valían como derecho nacido de la práctica, en tal sentido propio y válido con preferencia - y aun ocasionalmente contrario - al ius commune doctrinal y al derecho regio, común en el territorio considerado ("usus mercatorum praevalet juri communi... etiamsi contrarium disponeret", leemos en Casaregi y sus difundidos Discursus legales de commercio, 1740), con énfasis particular en la materia de contratos; a veces los usos podían recogerse por escrito en statuta $\mathrm{u}$ ordenanzas del arte o corporación mercantil, mediante el ejercicio de una sólida autonomía jurisdiccional (aunque, razonaban los mismos expertos, con bajo rango: una iurisdictio stricte sumpta, dependiendo el texto corporativo de su aprobación por autoridades de condición superior) que supo extenderse en los casos de mayor influencia

5 Cf. Roy Garré, Consuetudo. Das Gewohnheitsrecht in der Rechtsquellen- und Methodenlehere des späten ius commune in Italien (16.-18. Jahrhundert), Frankfurt am Main, Vittorio Klostermann, 2005, pp. 244-245. Antes, Antonio Padoa-Schioppa, "Giurisdizione e statuti delle arti nella dottrina del diritto commune" (1964), ahora en sus Saggi di storia del diritto commerciale, Milano, LED - Edizioni universitarie de Lettere, Economia, Diritto, 1992, 11-62. Puedo añadir por mi parte la prueba negativa que aporta un (mediocre) tratado hispano: Pedro de Salazar, De vsv et consvetvdine et de stilo cvriae regalis... [Granatae], Ex officina Regnerij Rabut, 1579, sin referencias de interés. a toda la ciuitas $^{6}$. En tales ocasiones, también cuando se aludía sin más a los usos del comercio, los juristas justificaban con alguna prisa su inhibición en un terreno que apenas les concernía: la proclamada especialidad del proceso mercantil - el conocido rechazo a la intervención de expertos en derecho ("aequitas in curia mercatorum praecipuè spectanda est, \& ex bono, $\&$ aequo in causis forum procedendum reiectis iuris apicibus") - fue la parábola utilizada para expresar un universo normativo diferente. Y sólo unas cuantas instituciones, no siempre usadas por los comerciantes en exclusiva (seguros, cambios, compañías), merecieron tratamiento monográfico ${ }^{7}$.

6 Por ejemplo, mediante la inclusión de las normas mercantiles en los estatutos locales, como en el caso de Milán (1396) (Padoa-Schioppa cit. [n. 5], p. 30, n. 69), cuando no se trataba de una ciudad cuya población toda ejercía, iuris tantum, la profesión mercantil (genuensis, ergo mercator: cf. Rodolfo Savelli, "Between Law and Morals: Interest in the Dispute on Exchanges during the 16th Century", en Vito Piergiovanni [ed.], The Courts and the Development of Comercial Law, Berlin, Duncker \& Humblot, 1987, 39-102).

7. A veces de una manera oblicua, esto es, no circunscrita a la esfera mercantil: en el caso del contrato de sociedad, vid. Pietro degli Ubaldi, De duobus fratribus, Venetiis, [Fraciscus Zilettus], 1584-1586; para las figuras concursales, Francisco Salgado de Somoza, Labyrinthus creditorum concurrentium ad litem per debitorem communem inter illos causatam... Venetiis, Apud Turrinum, 1653. Por supuesto, los juristas afirmaron su autoridad para aconsejar a los jueces gremiales, al ser expertos del rigor iuris: "nota... contra ignaros, imperitosque mercatores, qui se aequitatis magistros esse credunt, et inquiunt Iurisconsultum cauillatores concupiscere, \& sequi, mercatores verò aequitatem. Longè enim melius quid aequitas sit, Iurisconsulti noscunt, quàm ipsi quid sit rigor, qui aequitati opponitur: nam contrariorum est eadem disciplina", en Benvenuto Stracca (et al.), De mercatvra decisiones, et tractatvs varii, et de rebvs ad eam pertinentibvs... Lvgdvni, expensas Petri Landry, 1593 , p. 541. 
Si se acepta la rápida descripción que antecede bastaría con examinar los estatutos y ordenanzas mercantiles para disponer de una información excelente, seguramente más accesible que los tratados jurídicos por la lengua en que fueron redactados, sobre las costumbres de los mercaderes. Las especialidades del proceso, las disposiciones sustantivas aplicables, los modos de selección y el poder atribuido a las autoridades gremiales... se encontrarían allí suficientemente descritos, de modo que la tarea del historiador se limitaría a registrar con fidelidad notarial el testimonio contemporáneo de los documentos.

Sin embargo, las cosas no resultan tan sencillas. No me refiero ahora a la reducción - imposible - de todos los usos no escritos a normas fijadas gracias a la escritura, de lo que se deriva actualmente un grado de conocimiento historiográfico menos que fragmentario; tampoco quiero aludir a las transformaciones habidas al expresar en términos técnico-jurídicos valores y conductas profesionales, nacidos con un espíritu diferente $^{8}$. Y no sería necesario complicar el escuálido panorama con las exigencias impuestas 'desde arriba' a textos pendientes de autorización, sometidos entonces a equilibrios y compromisos de varia suerte. $\mathrm{El}$ caso es que, al menos hasta las famosas Ordenanzas del Consulado de Bilbao (1737), difundidas por el ámbito hispano y muy

8 Surge por aquí la cuestión de los conocimientos jurídicos de los mercaderes de antiguo régimen, un argumento aún por estudiar al que introduce Roberto Savelli, "Modelli giuridici e cultura mercantile tra XVI e XVII secolo", en Materiali per una storia della cultura giuridica 18 (1988), 3-24. completas en razón de la materia ${ }^{9}$, el contenido de los estatutos de la clase mercantil presenta una selección temática notablemente limitada. Las tales ordenanzas - lo mismo valdría para los juristas que elaboraron obras específicas sobre los mercaderes y sus tratos, basadas en la tradición doctrinal y el derecho general del reino ${ }^{10}$ - contienen, claro está, múltiples referencias a los usos del comercio al tratarse de un tópos que otorgaba legitimidad a la regulación corporativa, mas la disciplina allí asentada se refería a la vida institucional y sus privilegios, con alguna atención al préstamo marítimo y al seguro ${ }^{11}$. De modo que esas fuentes tan obvias no resultan, en mi opinión, un instrumento demasiado útil para comprender las costumbres de los mercaderes, sobre todo si otorgamos al término el contenido amplio más arriba recogido.

Tampoco resuelven nuestro problema aquellos pocos libros sobre derecho del

9 Afirmación que debemos aceptar a beneficio de inventario: hace bastantes años, al estudiar el contrato de compañía según la regulación de esas Ordenanzas (cf. capítulo 10), pude apreciar la riqueza de una práctica negocial malamente recogida en los preceptos consulares. Cf. Carlos Petit, La compañía mercantil bajo el régimen de las Ordenanzas del Consulado de Bilbao (1737-1829), Sevilla, Universidad, 1980.

${ }^{10}$ Por ejemplo, el difundido Laberinto de comercio... (1603) del enigmático Juan de Hevia Bolaños (ca. 1570 - 1623); la escasez de remisiones doctrinales a la costumbre aparece también en Benvenuto Stracca. Sin embargo, en el tratadito De nauibus de este autor (ed. cit. [n. 7], pp. 456 ss.) se contiene una aislada referencia, realmente un criterio hermenéutico de valor general $\left(\mathrm{n}^{\circ}\right.$ 9,p. 463: "Contractus enim à consuetudine contrahentium, \& loci interpretationem recipiunt... omnis dispositio à consuetudine interpretationem recipit, \& secundum illam partes contraxisse dicendum est").

${ }^{11}$ Cf. Carlos Petit: "Derecho mercantil: entre corporaciones y códigos", en AA.VV., Hispania. Entre derechos propios y derechos nacionales, Milano, Giuffrè, 1990, 314-500, pp. 333 ss. 
comercio elaborados por comerciantes de profesión ${ }^{12}$ - aun contando con títulos tan oportunos como Consuetudo, vel, Lex Mercatoria (1622) del inglés Gerard Malynes o Le Parfait Négociant (1675) de Jacques Savary ${ }^{13}$. En el índice de este último tratado - tan analítico y exhaustivo como es propio de los libros barrocos - falta por completo la voz 'coutumes'; se emplea al contrario usance, mas sólo con el sentido cambiario que el lector puede sospechar: equivalente al italiano (o español) uso, tal cual recogido por Savary, se expresa de tal forma el término habitual en cada plaza para pagar o aceptar un efecto girado sobre la misma. Obras posteriores, siempre con Savary de referente, lógicamente no enriquecen mucho más ese negativo panorama ${ }^{14}$.

12 Jochen Hook - Pierre Jeannin (Hrg.), Ars mercatoria.Handbücher und Traktate für den Gebrauch des Kaufmannes, 1470-1820. Eine analytische Bibliographie in 6 Bänden, I: Paderborn etc., Schöningh, 1991; II: 1600-1700, ibd. 1993; censo de literatura mercantil, aún en curso de publicación, donde las obras jurídicas componen una reducida minoría.

${ }^{13}$ Gerard Malynes (1586-1641), Consuetudo... que utilizo en facsímil (I-II, 1981) de la tercera edición (London 1686), con añadidos (tomo segundo) de Richard Zouch (The Jurisdiction of the Admiralty of England Asserted), G. Miege (The Ancient Sea Laws... Rendered into English...) y Sir John Burough (The Sovereignty of the British Sea); Jacques Savary (1622-1690), Le parfait négociant, ou instruction générale pour ce qui regarde le commerce de toute sorte de merchandises, tant de France, que des Pays Etrangers... en Oeuvres de Mr. Jacques Savary... ed. de Jacques Savary Des Bruslons, I, Paris, chez les Frères Etienne à la Vertu, 1763. Sobre el título de Malynes y sus ediciones, vid. Jochen Hook - Pierre Jeannin (Hrg.), Ars mercatoria cit. (n. 12), II, ref. M5.1-6, pp. 348 ss; sobre Savary, ibd. ref. S6.1-33, pp. $488-497$.

${ }^{14}$ Cf. Jacques Savary, Parères ou avis... en Oeuvres cit., II, parère xvi, p. 111; también, Encyclopédie méthodique, ou par ordre de matières. Commerce, III, à Paris, chez Pancoucke, 1784, pp. 825-886, donde vemos
Por su parte, el libro de Gerard Malynes ${ }^{15}$ parecería encaminado derechamente hasta nuestra cuestión: “Lex Mercatoria... and not Jus Mercatorum; because it is a customary Law, approved by the Authority of all Kingdoms and Commonwealths, and not a Law established by the Soveraingty of any Prince... And even as the roundness of the Globe of the World is composed of the Earth and Waters; so the Body of Lex Mercatoria made and framed of the Merchants Customs and the Sea-Laws" (ibd. "To the Courteous Reader"). Sin embargo, los conocimientos jurídicos del autor inglés eran muy sólidos (cf. pp. 3-5, con una larga lista de los tópicos - "subtilties" - al uso entre "Doctors and learned of the civil Law", esto es: de la definición básica quid sit Mercator a la duda "what Merchandise is fit to trade") y abarcaban bastante más que una simple descripción de prácticas profesionales: "to give satisfaction to the Learned and Judicius, I have abstracted the observations of the Learned in the Civil Laws... without naming any particular Autor, to avoid ambiguity and uncertainty to the content of this Book" (p. 6). La LexMercatoria

aún una acepción de usance como equivalente a usages et coutumes, "mais il n'est plus employé dans ce sens".

15 Malynes acuña una expresión - lex mercatoria destinada a lograr universal fama, significando como se sabe el derecho extralegal y paraestatal que gobierna el mundo del comercio; sin embargo, en su día fue un título más bien convencional en la producción libraria inglesa: vid. George Petyt, Lex parliamentaria: or, A Treatise of the law and customs of parliaments, London, Printed for J. Staag, ${ }^{2}$ 1690; Samuel Carter, Lex customaria: or, A Treatise of copy-holds estates...London, Printed by the assigns of R. and E. Atkins for D. Brown [etc.], ${ }^{2} 1701$; William Nelson, Lex Testamentaria: or, A compendious system of all the laws of England... concerning last wills and testaments... London, In the Savoy. Printed by J. Nutt for T. Bever, 1714. 
de Gerard Malynes era, en conclusión, a pesar de sus protestas también ius mercatorum; contenía las cuestiones y reglas del ius commune en materia de comercio ( $\mathrm{sin}$ olvidar una descripción de los iura propria principales) y se insertaba con ello en una larga tradición jurisprudencial ${ }^{16}$.

Ahora bien, la acentuada índole jurídica del tratado no sustituye por completo un contenido original, diseñado en función de sus destinatarios naturales. El universo de los saberes mercantiles ("what a compleat Merchant ought to know concerning the course of merchandising") constituye el "method observed in this Book", de manera que la disciplina del Law of Merchants termina por quedar subordinada a las necesidades materiales de la profesión. Un rico catálogo de argumentos, de la "science of Arithmetic" a la cronología, los pesos y medidas, la geometría y la cosmografía, los intereses y cambios, los fletes, los derechos de aduana... en fin, "the three Essentiall parts of traffick, being Commodities, Money and Exchange... by Bils of exchanges" aportan la sustancia de la obra, así suficientemente descrita.

${ }^{16}$ Malynes cit. (n. 13), p. 3, con sus evidentes errata: "Bartolus, Baldus, Justinian, Ulpian, Paul the Jurisconsultu, Papinian, Benvenuto Straccha, Petrus Santern, Joannes Inder, Balduinus de Vbald, Rodericus Suarez, Jason, Angel, Andrias Tiraquell, Alciatus, Budeus, Alexander Perusius, Pomponius, Incolaus Boertius, Azo, Celsus, Rufinus, Mansilius, Sillimanus, Accursius, Franciscus Aretinus, Grisogonus, Lotharius, Julianus"; podría aún añadirse sir John Fortescue. Tengo para mí que el autor escribía a la vista de la edición lugdonense de los escitos de Stracca y otros (precisamente: Nider, Baldo, Angelo Perusino, Pedro de Santarem, Rodrigo Suárez...) que aquí se han utilizado. Para el derecho propio de ciertos reinos europeos (Inglaterra, Aragón, Francia, Alemania), expuesto por Malynes en curiosa perspectiva comparada, cf. part iii, chap. xvii, pp. 314 ss.
¿A ese contenido se reduciría entonces la costumbre mercantil? Digamos más bien que Malynes disertaba en los términos habituales - la ciencia del comercio, con más o menos añadidos modernos, ya había quedado fijada desde las primeras prácticas de mercatura compuestas a fines de la edad media $^{17}$ - aunque silenciaba, pues presuponía (sin llegar a ocultarlas por completo), las auténticas costumbres que conformaron la cultura del mercader.

El transfondo de creencias, valores profesionales y modos de comportamiento que dieron sentido a unos saberes mejor o peor adquiridos y a las reglas del tráfico comienza por una declaración confesional. Y no hay que abandonar para comprobarlo el recordado libro de Malynes. Allí leemos, en efecto, que el designio de Dios en la creación repartió de forma diferente las riquezas naturales y las aptitudes de los hombres, de manera que el comercio ("first in real enterchange and communications of things of the same or other kinds... and after... by a commune pignus current mutuall, which we call money") fue una consecuencia espontánea

${ }^{17}$ Carlos Petit, "Mercatura y ius mercatorum", en C. P. (ed.), Del ius mercatorum al derecho mercantil, Madrid, Marcial Pons, 1997, 15-70, en particular pp. 32 ss sobre el catalán Llibre de conexenses de spícies, pp. 34 ss sobre Cotrugli [Kotrulic], Libro dell'arte di mercatura; cf. también De los Heros cit. (n. 1), pp. 5 ss [Semanario Erudito XXVI, pp. 149 ss]. Por lo demás, la revisión de cualquier vieja biblioteca de comerciantes permite comprobar la predilección por las temáticas enumeradas: cf. por ejemplo Carlos González Echegaray, "La biblioteca de un comerciante bilbaino del siglo XVIII", en Homenaje a Federico Navarro... Madrid, Asociación Nacional de Biblotecarios, Archiveros y Arqueólogos, 1973, 169-181; Antonio García-Baquero González, Libro y cultura burguesa en Cádiz: la biblioteca de Sebastián Martínez, Cádiz, Fundación Municipal de Cultura, 1988. 
de la distribución divina de los recursos, así también previsto y querido por el mismo Creador; resultó de ello un Law Merchant, unas normas establecidas para regular el juego natural de intercambios que serían el ordenamiento más antiguo de todos los conocidos, anterior incluso a la ley mosaica (chap. i, p. 2). La breve historia sagrada del comercio que ofrece a continuación Malynes (el pastor y padre Abraham compró con monedas un lugar para enterrarse; los hijos de Jacob se encontraron con mercaderes; el casto José negoció en Egipto...) justifica la antigüedad de las actividades mercantiles, pero sobre todo imparte una lección de legitimidad en el ejercicio de una santa profesión, reclamada por la naturaleza y naturalmente ordenada según normas racionales: ningún ejemplo mejor que la $l e x$ mercatoria, enseña el autor, de la definición ciceroniana del derecho (recta ratio, natura congruens, diffusa in omnes, constans sempiterna). Si volvemos por un instante nuestra atención a la obra célebre de Jacques Savary - son lazos de unión y caridad entre cristianos la auténtica esencia del comercio; la historia de los tratos y contratos se presentaría, en realidad, como ámbito intemporal de virtudes y de sociabilidad aristotélica - la palpable comunidad de ideas demuestra un pensamiento ampliamente difundido ${ }^{18}$.

Veremos muy pronto que la naturalidad, la universalidad y la prosapia del comercio acompañan al derecho mercantil hasta los tiempos actuales. Pero sigamos todavía en los pretéritos, aquellos tiempos de un ius mercatorum y una lex mercatoria transidos

18 Parfait négociant cit. (n. 13), prél. part., I, chap. i, "De la nécessité du Commerce", p. 1. de religión. Nadie desconoce que el valor constituyente de la fe religiosa otorgó sentido a cualquier actividad de relevancia durante el antiguo régimen, mas resultaba obligado recordar ahora una obviedad que encierra motivos particulares en relación a las empresas mercantiles: según se afirmó con insistencia, ningún ejercicio profesional ha tenido un valor apostólico tan claro; ninguna práctica como el comercio para extender las creencias cristianas ${ }^{19}$.

Por una parte, la condena de la usura ampliada hasta significar, sin más, mera improductividad del dinero ${ }^{20}$ - colocó la mercatura en los márgenes morales de la experiencia preliberal. Las pruebas de la antigüedad y sacralidad del comercio desempeñaron entonces la misión de apuntalar la licitud de una profesión asaltada por la sospecha ${ }^{21}$. Y es que el dinero podía ofrecer

19 Johann Lassenius, Bürgerliche Reiss- und Tischreden. In zwölf nützliche und anmutige Gespräch abgetheilt... Nürnberg, in Verlegung Johann Andreas Endters und Wolffgang des Jüngern seel. Erben, 1662, pp. 54 ss. "Von dem Kaufhandel in gemein, dessen Ursprung, Lob und Nutzbarkeit". Cf. Ars mercatoria cit. (n. 12), II, ref. L14.1-2, p. 296.

${ }^{20}$ Además de Bartolomé Clavero, Usura. Del uso económico de la religión en la historia, Madrid, Tecnos, 1984, para la edad moderna, reconstruye perfectamente los orígenes de la represión Umberto Santarelli, "La prohibición de la usura, de canon moral a regla jurídica. Modalides y éxitos de un transplante", en Petit (ed.), Del ius mercatorum cit. (n. 17), 237-256.

${ }^{21}$ Cf. Malynes cit. (n. 13), pp. 225 ss, con un repaso de autoridades, a partir de la Biblia, "Of the Laws and Prohitions against Usury" y la originalísima alegoría de San Jorge (el rey cristiano) que combate al dragón (la usura) para liberar a la doncella (el alma pecadora de los cristianos). El dragón (a veces, por consideraciones superiores, un mal admisible: a necessary evil) tiene como alas la usura palliata y la usura explicata (cf. pp. 241 ss, "Of Usurius Contracts"); su peligrosa cola es el cambium. Los capítulos siguientes abordan la usura tolerada y la prohibida, así como montes y bancos. 
múltiples ocasiones al pecado, pero también el dinero había sido el modo de vida de Mateo, un apóstol más digno que el humilde pescador Pedro al ser más exigente su vocación: de un banquero que todo lo dejó por Cristo "ben possono preggiarsi i Negocianti" 22 .

Por otra parte, la búsqueda de legitimidad religiosa y moral dio sentido a variadísimas prácticas piadosas, tanto individuales como corporativas, que hoy despreciaríamos en su alcance más profundo de no situarlas en el corazón mismo de las costumbres del comercio. Porque la negociación - incluida la más escrupulosa - provocaba "mil pecadillos", que sólo una restauración de la justicia conmutativa dañada en los tratos podría hacer perdonar. Y a tal fin sirvió la práctica de la limosna: "item deuen [los comerciantes] ser muy limosneros como gracias a Dios lo son en estremo los de estas gradas [de Sevilla]: porque demás de la obligación general que a ello tienen todos los fieles: corre en ello vna particular, conviene a saber, que mercando y vendiendo a la continua no pueden tanto apurar el justo precio que no peque por carta de más a las vezes el que vende, o por de menos... el que compra, do se incurren sin sentirlo dos mil carguillos de restitución: de los cuales se descarga con la limosna". De lo individual a lo corporativo, en esas sabias advertencias de un experto confesor de la carrera de Indias "mi intento es solo escriuir de lo que se vsa

${ }^{22}$ Gio. Domenico Peri, Il Negotiante... Parte seocnda, Venezia, Presso Gio. Giacomo Hertz, 1697, cap. i, "Veri Mercanti quali sono, loro qualità, e come si distinguono le Negotianioni", pp. 2-3. Cf. Ars mercatoria cit. (n. 12), II, ref. P11.19-22, pp. 433-434 sobre esta edición. en mi tiempo, y en nuestra tierra"23encontramos además la razón de las inevitables disposiciones sobre ceremonias religiosas y liberalidades realizadas por cuenta del gremio, que tanto abundan en la vieja normativa mercantil ${ }^{24}$.

En la línea anunciada, puede bastar ahora con presentar el caso del Consulado de Burgos - matriz de las corporaciones de mercaderes creadas en Castilla e Indias cuyas Ordenanzas de 1538 son ricas en referencias a las limosnas institucionales. La principal ocasión de su reparto coincidía con la elección de los magistrados gremiales, por lo demás rodeada de ceremonias religiosas: celebradas en el monasterio de San Juan, por la fiesta de San Miguel, era el momento de dispensar miles de maravedíes en misas y pitanzas para los monjes; había aún más donativos a favor del hospital monástico, los pobres de la cárcel y otros centros religiosos de la ciudad ("porque rueguen á Dios Nuestro Señor que guíe las cosas de la dicha universidad para su servicio", ord. iv, pp. 178-182). Pero el prior y los cónsules podían repartir nuevas sumas sin autorización previa del gremio, aparte los socorros ("todas las veces que se ofrecieran") a favor de los marineros arruinados por un naufragio o por el corso (ord. xxxvi, p. 225). El Consulado sufragaba también una misa diaria en la iglesia de San Lorenzo (Llorente), con toque

${ }^{23}$ Fray Tomás de Mercado, Tratos y contratos de mercaderes y tratantes discididos y determinados... Salamanca, Matías Gast, 1569, pp. 13 vta.- 14, p. 129 vta. Cf. Ars mercatoria cit. (n. 12), I, ref. M18.1-4, pp. 148-149.

24 Eloy García de Quevedo y Concellón, Ordenanzas del Consulado de Burgos... Burgos, Impta. de la Diputación, 1905. 
o aviso de campanas "para que el Prior é Cónsules é todas las personas que se hallaren a la sazón en la Llana é casa del Consulado á su ayuntamiento é negociaciones puedan, los que les pluguiere, oyr la dicha misa, é por estar tan conjunta la dicha yglesia... es gran aparajo para que la oyan todos é sea Nuestro Señor servido" (ord. xiii, p. 192). Esas prácticas y dispendios de caridad, puestas por escrito en las Ordenanzas ("no ostante que sean cosas de limosnas y como manda Nuestro Señor se han de hacer en secreto") para asegurar su cumplimento ("por el bien y exemplo de los subcesores de esta universidad, é dar causa á que se prepetúen é conserven") sólo desaparecieron en 1766 , cuando se refundó sin mucho empuje el viejo consulado burgalés.

La religión se hermanó como vemos al comercio y las liturgias y creencias cristianas ofrecieron el marco general que dio sentido a las costumbres de los mercaderes ${ }^{25}$. En un alarde de coherencia el espacio literario del antiguo régimen reservó a la disciplina de los tratos un capítulo específico dentro de la teología práctica... en detrimento de los saberes jurídicos, convirtiéndose el criterio de los moralistas en la fuente primera del

25 Sobre la vocación pública y las obras de caridad de los Cinco Gremios de Madrid, principal entidad mercantil de la España ilustrada, informa todavía Juan Antonio de los Heros cit. (n. 1), pp. 108 ss [Semanario Erudito XXVI, pp. 252 ss]. Mas, en general, el horizonte confesional del comercio asalta al lector de cualquier tratado de mercatura; así, la obra cit. (n. 22) de Peri, Il Negotiante, II, p. 53: "la virtù della Liberalità più d'ogn'altra fà conoscere per simili à Dio nell'operare, perche più d'ogn'altra discuopre in noi la ragione del buono, c'ha per naturalezza il communicarsi ad altri... Consideri il Negotiante se vuole contrattare ad imitatione di Dio (il quale questo nome di Negotiante nel Vangelo più volte s'appropria)". régimen contractual ${ }^{26}$. Desde inicios del siglo XVI - una centuria abierta con encendidos debates sobre la licitud de los intereses (15131515 ) - hasta mediados del siglo XVIII cuando la encíclica Vix pervenit (1744) del papa-canonista Lambertini (Benedicto XIV) relanzó en el sur de Europa la añeja cuestión de la productividad del dinero - las relaciones entre mercaderes, teólogos y juristas fueron muy intensas y modelaron las estrategias y usos comerciales ${ }^{27}$; es suficiente recordar al respecto la fortuna del contrato trino (contractus trinus, contractus triplex), extraña combinación de un pacto de sociedad (entre un capitalista y un comerciante que granjea el dinero), un segundo acuerdo de seguro (el capitalista renuncia a una parte de sus ganancias, como prima por la garantía que presta el mercader financiado de devolución del capital) y un tercer contrato de venta (de los beneficios que tocarían al inversor, compensado a su vez mediante un precio predeterminado que pagará el comerciante). Sería apasionante reconstruir la historia de un negocio tan difundido como dudoso (como que libraba del riesgo por

26 Es muy ilustrativo el índice de materias de Nicolás Antonio, Bibliotheca Hispana Nova, II, Matriti, Apud Viduam et Heredes Joachimi de Ibarra, 1788 (ed. facs. Madrid, Visor Libros, 1996), pp. 535 ss, con apartado "de iustitia et iure et contractibus" (p. 566) en el capítulo "Moralia, theologica, philosophica, politico-moralia" (pp. $562 \mathrm{ss),} \mathrm{carente} \mathrm{de} \mathrm{similar} \mathrm{entre}$ los títulos jurídicos.

27 Cf. Savelli, "Between law and morals" cit. (n. 6); Carlos Petit, "Signos financieros y cosas mercantiles, o los descubiertos de la Ilustración cambiaria”, en Vito Piergiovanni (ed.), The Growth of the Bank as Institution and the Development of Money-Business Law, ibd. 1993, 225-310. La edición de discursos de De los Heros antes cit. (n. 1) incluye un dictamen teológico sobre contratos a intereses (1763). 
pérdida del capital a la parte inversora), mas ese raro contrato, debatido durante siglos, nos vale aquí como muestra de la incidencia de la religión en la vida mercantil ${ }^{28}$.

Y no se trataba de buscar recovecos o argucias probabilistas que permitieran escapar del rigorismo vigente en la contratación. Aunque hubo desde luego matices - la relajación de los genoveses, estrechamente vigilados por los teólogos más famosos, contrastó con la rígida moral castellana ("si nos atrebiesemos a la conzienzia como ellos bien lo sabríamos hazer, y tan bien como ellos" ${ }^{29}$ - describimos ahora valores compartidos, creencias características de un horizonte cultural presente en las acciones, los gozos y los temores de hombres y mujeres de carne y hueso. Por eso, de entre los abundantes testimonios que cabría alegar recojo al azar unos casos procedentes de Cádiz, la zona que, aún antes de recibir el monopolio

28 Cf. Alberto García Ulecia, "El contrato trino en Castilla bajo el derecho común", en Historia.Instituciones. Documentos 6 (1979), 129-185; Italo Birocchi, "Tra elaborazione nuove e dottrine tradizionali. Il contratto trino e la natura contractus", en Quaderni fiorentini per la storia del pensiero giuridico moderno 19 (1990), 243-322.

29 Son expresiones del banquero Simón Ruiz, en carta de 30 de junio de 1569 a Antonio de Quintanadueñas, que recoge José Martínez Gijón, "La comenda-depósito" (1964), ahora en Historia del derecho mercantil. Estudios, Sevilla, Publicaciones de la Universidad, 1999, p. 90. Para Génova, cf. Rodolfo Savelli, "Between law and morals" cit. (n. 6), pp. 58 ss con uso de la correspondencia cruzada entre Diego Laínez e Ignacio de Loyola; pero no hay dudas de que la laxitud moral se compensó en la república marinera con un plus de caridad, no existiendo "in Italia cità alcuna ove tanto danaro si profonda in elemosine ed ove s'incontri copia maggiore di mendicanti" (cf. Edoardo Grandi, La repubblica aristocratica dei genovesi. Politica, carità e commercio fra Cinque e Seicento, Bologna, Il Mulino, 1987, testimonio de época en p. 303). del comercio ultramarino, constituyó foco principalísimo del tráfico peninsular.

Tan principal, como para atraer a una nutrida colonia de mercaderes extranjeros, generalmente factores y comisionistas que representaban los intereses de largas redes mercantiles repartidas por los cuatro rincones de Europa. Uno de ellos, el saboyano Raimundo de Lantery, ha dejado un raro libro de memorias con vivencias y experiencias tenidas en el último cuarto del Seiscientos ${ }^{30}$. Allí se nos presenta a un Juan Munurga, rico colega amigo del diarista que "quiere ser pobre y Dios quiere que no lo sea", tal vez porque "de lo que ganaba cada año, hacía tres partes: la una para el gasto cotidiano de la casa, otra para los pobres y conventos de Cádiz y la otra para los conventos de pobres de fuera del lugar... No hay nadie en Cádiz que no le tenga alguna obligación directa o indirecta... siempre procuró hacer gusto a todo el mundo" (p. 253). La descripción de la generosidad de Munurga, recientemente fallecido cuando sobre él escribe Lantery, tal vez pudo arrastrar la exageración del elogio póstumo, pero la lectura completa del diario nos demuestra que la piedad del amigo no fue un sentimiento excepcional. "Hay dos temas que dominan poderosamente la personalidad de Lantery", advierte con acierto su editor, "el binomio honra-honor y, sobre todo, el componente religioso" (p. 59). Y en efecto, las pruebas de la religiosidad de Lantery salpican aquí y allá su escrito, sin que nos resulte extraordinario encontrar una

30 Manuel Bustos Rodríguez (ed.), Un comerciante saboyano en el Cádiz de Carlos II. (Las memorias de Raimundo de Lantery, 1673-1700), Cádiz, Caja de Ahorros, 1983, que une a la edición un interesante estudio introductorio. 
interpretación confesional de los mil aconteceres de la vida ordinaria. Así, cuando un Gasparini le propone formar compañía ese vínculo tan estrecho que unía a lo puramente comercial el establecimiento de relaciones cuasi familiares y la asunción compartida de riesgos, según enseguida veremos - el saboyano acepta la asociación por tratarse su colega de hombre "muy inteligente y religioso, quieto, sin vanidad y muy cabal en todas sus cosas" (cf. p. 39). Del cargador Juan Bernardo Grosso, para quien trabaja Lantery de contable, destaca en las memorias su generosidad y afición a sostener económicamente festejos y celebraciones religiosas en la plaza de Cádiz (cf. p. 50). Y en fin, a propósito de un Manuel Fiallos, dueño de géneros que salen indemnes en una ocasión de peligro, se concluye que la razón de tan admirable suceso descansaría en el destino de las ganancias esperadas para el culto del Santo Sacramento (cf. pp. 66-67).

La convicción religiosa se hizo presente en la vida mercantil y palpitó en las acciones de esos viejos comerciantes. Otro habitual de la carrera de Indias, el onubense Manuel Rivero, varias décadas después de Lantery todavía participa de la misma cultura ${ }^{31}$. Cuando escribe, comido por las deudas, a su

${ }^{31}$ Sobre la saga mercantil de los Rivero, con importante documentación inédita del archivo familiar, cuya noticia ahora le agradezco, vid. Alfonso Pleguezuelo Hernández, Manuel Rivero. Los encargos artísticos de un mercader andaluz del siglo XVIII, Huelva, Diputación de Huelva, 2005. Cf. José Garmendía Arruebarrena, Tomás Ruíz de Apodaca, un comerciante alavés con Indias (1709-1767), Vitoria, Diputación Foral de Álava (Dpto. de Cultura), 1990, de inferior valor pero útil contraste: $v i d$. pp. 199 ss de "ética y moralidad en el negocio", pp. 243 ss sobre las prácticas religiosas de Apodaca. hijo Juan Gerónimo en relación a una moratoria le pide "guardar todo sigilo, y si esta llega a tiempo el día de nuestro santo, es preciso que esa casa haga una demostración de misa cantada al Sr. San José y una limosna de comida y pan a nuestros queridos los pobres abundantes. Dicen que Dios da 100 por uno; mienten, que no tiene número lo que da Dios" (carta de 17 de marzo, 1768) ${ }^{32}$. Las intervenciones milagrosas en los negocios poblarían también el mundo de creencias de los Rivero si unos días después de aquella fecha el patriarca Manuel vuelve a escribir con incontenida alegria: "acabo de tener carta de Cristóbal [otro de los hijos, su agente en la Corte]... en que me dice que... se publicó en el Consejo Pleno de Indias la Real Gracia y Resolución de S.M., no quedando ya, mediante Dios, ni su infinita misericordia, qué hacer, y según las oposiciones y las amplitudes tan grandes como viene la demoratoria, es todo un milagro de Dios... Hijo de mi alma, con gran humildad ofrezcamos a Dios tan grandes beneficios... Dios es padre, y yo tengo gran fe, y según vamos experimentando aquí en la demoratoria... nos hemos de ver desempeñados antes de lo que pensamos" (carta a Juan Gerónimo de 23 de marzo, 1768). Oportunísima resolución para un mercader en apuros, que sabe ver en la concesión regia - escribe ahora a su esposa, Juana Inocencio Cordero, residente en Ayamonte una gracia especial "de nuestra madre del Carmen, fundadora y portera de tu casa" (carta de 17 de marzo, 1768).

${ }^{32} \mathrm{O}$ en expresiones de Raimundo de Lantery cit. (n. 30), p. 185, "cuando el mundo no me lo pague, Dios me lo pagará a su tiempo". 
La inclinación piadosa de Manuel Rivero hacia la Virgen del Carmen, fraguada durante los años de su estancia en Indias, le había llevado a invertir sus primeras ganancias en la compra de una mala tabla mexicana de tal advocación ${ }^{33}$. Y esa imagen de desmañada factura le acompaña de por vida, como divinidad doméstica que siempre se hace presente en los momentos más entrañables. Así, mientras espera impaciente en Cádiz la arribada de uno de sus buques Rivero recibe carta de Juana ("estando ayer en el Trocadero recibí la tuya") y se conmueve tan hondamente al saber de su esposa que rompe en lágrimas y rezos: "te aseguro por nuestra Madre y Señora la Santísima Virgen, no me pude contener, hecho un mar de lágrimas; me cogió solo en el almacén alto, donde me pude desahogar dándole infinitas gracias a Dios. Como media hora después de la oración, fue que entró la fragata. Hija, estas cosas, como de fe, debemos creer, que la mano de Dios las mueve todas" (carta de 6 de enero, 1770). La Virgen marinera, pero también el mencionado señor San José, a quien Rivero agradece en alguna ocasión el haber salvado su vida (cf. Manuel al hijo Cristóbal Rivero, 1 de mayo, 1750) $)^{34}$, aparecen como los

${ }^{33}$ Se trata de un objeto devocional de dudoso gusto, con funciones de amuleto: Pleguezuelo cit. (n. 31), pp. 132 ss, con reproducción de la justamente calificada de "imagen talismánica". La advocación del Carmen designó además uno de los barcos de Rivero y la más apreciada de sus huertas: $i b d$. pp. 50 ss, pp. 96 ss.

${ }^{34}$ Al sufrir una enfermedad en las Indias, Rivero (1730) hace promesa a San José ("voto y promesa que yo Manuel Rivero hago a mi padre San José valiéndome del patrocinio de mi madre y señora Santa Teresa de Jesús para que suplique a Señor San José me sane de una quebradura") y lo recoge por escrito, a modo de contrato ("prometo y me obligo a dicho santo mi patrón y a hacerle todos los días del santo una fiesta de sermón y misa si dioscuros de la casa en un importante pleito con sus acreedores; conociendo las aficiones paternas, Cristóbal anuncia una sentencia favorable y recomienda especialmente que "vaya Vmd. y mi querida madre a dar gracias a Dios, a nuestra protectora la Santísima Virgen del Carmen y a mi señor San José" (carta de 7 de julio, 1772). Por eso, a pesar de su baja calidad, nada tiene de extraño que las disposiciones sucesorias de Manuel Rivero fueran muy puntillosas en lo tocante a la suerte del querido totem carmelitano ${ }^{35}$.

La devoción del mercader onubense - lo mismo valdría para Lantery antes que él y para el vasco Ruiz de Apodaca en su mismo tiempo - se trasmitía a los hijos, como elemento principal de la formación en el comercio. "Espero en Dios y en vuestro cuidado y actividad", escribe a José Antonio y Manuel en 1750 ( 8 de diciembre), "que la apliqueis al mayor beneficio de la venta de estos intereses, de manera que quedemos con

me sana... y en muriéndome, del quinto de mi alma que dejo para Nuestra Señora del Carmen, que sean por mi señora y Señor San José”). Cf. Pleguezuelo cit. (n. 31), p. 219.

35 En efecto, al establecer mayorazgo en 1761 dipuso el mercader"lo primero, destino por dote y capital de este bínculo como alaxa de mi mayor estimación, una lámina de nuestra señora del Carmen de media vara de alta y una tercia de Ancho, que está colocada sobre la segunda puerta de la calle de la cassa principal de mi morada, en dicha ciudad de Ayamonte en cuyo sitio deberá permanecer siendo obligación de los posehedores de él mantener luz encencida toda la noche a esta soberana señora cuya pención les Ympongo en attencion a ser esta Ymagen la primera alaxa que adquirí, con los primeros reales que agencié en la América siendo yo de hedad de cattorce años grangeando con su poderosa protección y amparo los demas vienes que la liberal y dibina mano me ha franqueado y en demostración de la gratitud que me asiste a tan singulares beneficios", testimonio de la carta de fundación que recoge Pleguezuelo cit. (n. 31), p. 132. 
todo el crédito, como lo espero, en toda dependencia que habeis recibido. Lo primero, a cumplir con Dios y el mayor adelantamiento de vuestro crédito, pues así me dareis todo gusto y redundará en vuestro mayor beneficio y ganar amigos del tamaño de esta casa, que es la más fuerte y que más crecidos riesgos hace a la América. Dios vos haga unos santos... pues es el día dichoso de la Purísima Concepción de Nuestra Señora, en quien espero que como buenos cristianos, habreis hecho las diligencias que el santo día requiere". El valor probatorio de esta documentación personalísima me resulta indiscutible.

Sin embargo, conviene dar un paso adelante y reparar en un par de conceptos utilizados por Rivero en su carta a los hijos Manuel y José Antonio. Derivaciones ambos del marco religioso - omnipresente como vemos en la práctica mercantil - ofrecen dos estrategias más, en sí mismas relativamente autónomas, para recrear la cultura y las costumbres del vsus mercatorum.

El primero se refiere al valor de la amistad. Un motivo que sirvió de armazón a los tratados mercantiles con sospechosa frecuencia ${ }^{36}$ y que, en lo tocante a su proyección más práctica (el logro de buenos amigos, mediante el adelantamiento del crédito y escrupuloso amor hacia Dios), fue la primera advertencia, recordemos, que hizo

36 Ya cité las Tischreden de Lessenius (n. 19), donde la doctrina mercatoria se ofrece a partir de las conversaciones mantenidas por un grupo de amigos. Un uso retórico del trato amical también se sigue por Alvise Casanova, Specchio lucidissimo, nel quale si vedeno essere diffinito tutti i modi, et ordini che si deue menare nelli negotiamenti della Mercantia, cambii, recambii, disgarbugliando, et illuminando l'intelletto a negotianti, Venetia, Comin da Trino, 1558 (cf. Ars Mercatoria cit. (n. 12), I, ref. C6.1-2, p. 61).
Rivero a sus hijos cuando pasaron a México. Cierto es que la amistad mercantil constituye una manifestación de los valores religiosos antes descritos, pues la cohesión corporativa, las devociones y cultos institucionales o la confianza recíproca de los contratantes serían meras derivaciones del vínculo amoroso existente entre los fieles de la misma confesión ${ }^{37}$; ahora bien, cuando los cristianos se dedican al tráfico, entonces los virtuosos sentimientos de amistad penetran en el terreno del comercio para convertirse, finalmente, en su mismo fundamento. Así, si las practicas de mercatura declinan las voces amigo, amico, friend... en referencia insistente al colega de profesión se trataría, antes que del empleo banal de un vocablo inespecífico, de una auténtica expresión de cultura, base de comportamientos y razón de peculiaridades institucionales.

Comportamientos y actitudes mercantiles, fundados en amistad ${ }^{38}$. Puede ser interesante

37 Tengo por supuesto presente el viejo entendimiento del amor en tanto lazo social, antes que como simple deseo íntimo: cf. António M. Hespanha, "La senda amorosa del derecho. Amor y iustitita en el discurso jurídico moderno", en Carlos Petit (ed.), Pasiones del jurista. Amor, memoria, melancolía, imaginación, Madrid, Centro de Estudios Constitucionales, 1997, 23-56, con sus debates (pp. 57 ss). Un discípulo del amigo Hespanha ha podido desarrollar el fascinante panorama: Pedro Cardim, O poder dos afectos. Ordem amorosa e dinâmica política no Portugal de Antigo Regime, tesis doc. (Historia), Lisboa, Universidade Nova, 2000, con su capítulo mercantil; como adelanto, del mismo autor, "Amor e Amizade na Cultura Política dos seculos XVI e XVII”, en Lusitania Sacra 11 (1999), 21-57.

38 Sobre la amistad y la cultura del don, con referencias que también aprovecharán al historiador de las costumbres mercantiles, vid. últimamente Natalie Zemon Davis, Essai sur le don dans la France du XVIe siècle (2000), Paris, Seuil, 2003, en especial pp. 33 ss para las recurrencias y sentidos del término amy. 
recordar la existencia de reglas y usos altamente formalizados para el mejor despacho de la correspondencia (esto es, "the life and soul of commerce"), donde el destinatario de la carta ha sido el dicho amigo o colega-contratante cuyo amor alimenta el propio giro epistolar; de ese modo me atrevo a explicar la admiración del comerciante ante el invento del papel, cosa grande, útil y segura, "perche in materia si sottile, e di così poco pesso si possono commodamente spiegare i concetti dell'animo, quali fidati à picciol foglio in se ristretto, e ben sigillato possono sicuramente caminare in ogni parte del Mondo, sinche gioto quello alle mani di chi è indrizzato e apertole il seno, compisca l'officio commessoli; e in questa maniera ancorche allontanati da longhissimo spatio di camino possono gl'Amici tratar insieme, consolatione veramente grande delle persone che s'amano, ma comodità grandissima della Mercatura" ${ }^{39}$. Sobre base semejante la atención doctrinal por las condiciones materiales del escritorio y aun por la disciplina corporal que debía seguir el escribiente ("the position of the Body, Desk, Seat, and Book or Paper, when you sit at writing", en

${ }^{39}$ Cf. Peri cit. (n. 22), Parte prima, cap. v, "Del modo di scrivere Lettere, Ordini, e Comissioni”, pp. 7-8; también cap. xi, "Del patrone, ó sia principale del Negotio", p. 28; cap. xiv, "Lettera d'offerta dimandata oblatoria, che si scriue nel principio della Compagnia di Negotij, e risposta con le considerationi sopra quelle", p. 36; en la parte tercera de la obra cit., con título aparte (sc. Ifrvtti d'Albaro, overo il Negotiante... Parte terza), se considera que el papel "imita... la Divina Omnipotenza col rendere presenti per mezo de' Scrittori le cose de' secoli trascorsi”' (p. 38). Finalmente, en la Parte quarta de la edición consultada los añadidos de Mattia Cramero, Il segrettario di Banco, overo stile di corrispondenza mercantile (cf. Ars mercatoria II, cit. (n. 12), ref. K9.1-15, pp. 275-278), arrancan de la ecuación "amici o corrispondenti". expresión de una obra muy leida $)^{40}$ ciertamente desempeñaron una función iniciática en la práctica del oficio ("his learning how to indite his letters in a tradesman's style, and to correspond like a man of business") ${ }^{41}$, pero también contenían una sentida preocupación por la claridad y belleza de los trazos en prueba de la rectitud moral que animaba al remitente: "perche vna ben composta, corretta e ben scritta lettera aggiunge riputatione, e fà, che coloro, i quali hanno da rispondere, vadino in tutti molto circospetti" 42 .

La nitidez caligráfica y el orden sereno de la frase encerraban así el respeto debido a los amigos y la honestidad que presidía la recíproca relación. Al menos, amistad y caligrafía se dieron la mano en el caso del recordado Lantery - un mercader que siempre presumió de experto contable y escribiente ${ }^{43}$

${ }^{40}$ Me refiero a la colección titulada The Universal Library of Trade and Commerce ... By the most Celebrated Masters, London, Printed for J. Robinson, 1747 , pp. 2 ss.

${ }^{41}$ Daniel Defoe, The Complete English Tradesman (1726-1727), I-II, London, printed for C. Rivington, 1732, I, let. ii, pp. 17 ss, obra, por cierto, presentada como una colección de "familiar letters"; además, The Universal Library cit. (n. 40), p. 1: "penmanship, in a Word, is the Life and Soul of Commerce and Correspondence: By the Practice of it we manage our Affairs at the greatest Distance and with all the Secrecy and Satisfaction imaginable". Para España, cf. Roberto Fernández Diáz-Carlos Martínez-Shaw, 'L’apprentisage de la correspondence par les commerçants espagnols au 18e siècle: le cas de Barcelonne", en Franco Angiolini Daniel Roche (eds.), Cultures et formations négociantes dans l'Europe moderne, Paris, École Pratique des Hautes Études en Sciences Sociales, 1995, 309-319.

${ }^{42}$ Il Negotiante... Parte prima cit. (n. 22), p. 9; cf. también cap. iii, "Dello scrivere”, pp. 5-6. Por otra parte, del estilo epistolar de Tomás Ruíz de Apodaca - "sereno, objetivo, prudente" - trata de pasada Garmendía cit. (n. 31), pp. 277 ss.

${ }^{43}$ Lantery se dedica a copiar panfletos contra el valido Fernando de Valenzuela, "con que hacía dos cosas 
pues el gaditano-saboyano en sus memorias "utiliza el vocablo amigo con relativa frecuencia", para expresar un sentimiento que "conlleva un servicio" y que no puede romperse "por causa de dinero": los amigos del comercio nunca habrían de resultar "gravosos unos con los otros" (Bustos cit. [n. 30] p. 29). Y en efecto, cuando Raimundo de Lantery establece tratos y amistad - tras aprovechar financieramente la mantenida con Juan Bernardo Grosso ${ }^{44}$ - con el sevillano Juan Ambrosio Pessio, presenta esta relación, en buen estilo mercantil, como un asunto de correspondencia: "quedamos de correspondernos, que así lo efectuamos luego que llegó a Sevilla... con que entablamos una muy buena correspondencia que era de crédito y útil para entrambos" (p. 183). El mismo mercader confiesa haber gastado cien pesos en dar cristiana sepultura a un colega extrajero, fallecido sin recursos (p. 197). Y otro tanto cabe observar, medio siglo después, en relación a Manuel Rivero, cuyas cartas nos reservan un magnífico testimonio - entre muchas posibles muestras ${ }^{45}-$ del compromiso

a un tiempo: la una pasaba mi ociosidad, la otra asentaba mi letra que hasta entonces no escribía bien" (cit. [n. 30]); poco tiempo después se coloca como escribiente de Juan Bernardo Grosso: "a mí me ocupó en escribir sus libros, porque tenía letra razonable como se ve; tenerle la pluma en escribir las cartas tanto en italiano como en español; y en copiar las cartas... y en acudir a los almacenes en cuanto se ofrecía” (p. 144).

44 "Este año [1682], don Juan Bernardo Grosso, habiendo experimentado mi legalidad y verdad, deseó adelantarme, pues me dio licencia de valerme de algún dinero de la caja, si hallaba ocasión de algún empleíto que me pudiese valer algo" (p. 183).

${ }^{45}$ Por ejemplo, un anónimo comerciante que envía ciertas muestras de lino se presenta como "el amigo de Tavira" (Alonso de Mena Fariñas a Manuel Rivero, 9 de junio, 1778), en tanto el mercader Thomas Wedding amistoso, ahora bajo forma de la ayuda prestada a unos buques franceses ("en ocasiones de honra es menester portarnos con las garbosidades precisas") en aguas de Portugal. "Ya sabes las muchas obligaciones y amistad que yo y nuestros hijos", escribe desde Cádiz a su mujer, "debemos a la nación francesa y los amigos particulares de ella, y que en ocasiones de honra es menester portarnos con las garbosidades precisas y echar el resto, por lo que sin faltar nada, espero nos dejarás airosos tú y Juan a mí y a nuestros hijos, luego, luego que recibas esta, pues ya sabes lo que ha sucedido en Lagos con la Armada inglesa y francesa. Despacharás a dicho Lagos nuestros dos faluchos... mandándole al capitán francés, que está en dicho Lagos, el sr. De la Clué, y por si Dios se lo hubiere llevado, al jefe que quedare en su lugar, cincuenta carneros, y por lo pronto se pueden tomar prestados de los de San Francisco o del convento de la Merced seis terneras pequeñas y si se hallaren a comprar ahí será mejor o en la Redodela 200 gallinas, algunos barriles del mejor vino, todo género de hortalizas menos uvas ni higos, y si no cupieren en los dos faluchos, en lo que cupiere, con la mayor brevedad, escribiéndoles Juan de su puño a los dichos jefes ofreciéndoles

puede ser informado, gracias a un conocido común, de los sentimientos estrechos que albergaba el onubense a su respecto ("por el afecto y amistad que [a] Vm. profeso", escribe a Rivero un Félix Martínez Espinosa, "paso a noticiarle que por cierta conversación que se ofreció con nuestro amigo el Sr. D. Thomas Wedding le manifesté las expresiones de agradecimiento y reconocimiento que $\mathrm{Vm}$. expresa conservarle en su carta de 4 de Junio, con el motivo de haberse llevado Dios para sí a nuestro amigo D. Ricardo Butler, a que dicho señor, enternecido, se explicó en términos muy sensibles", 10 de agosto, 1773). Cf. Pleguezuelo cit. (n. $31)$, pp. 44 ss. 
cuanto pidieren, y siempre que lleguen ahí oficiales, hospédalos en la casa de Jesús o en la casa del balcón o en cualquiera otra que Dios nos ha dado, administrándole todo cuanto necesitaren para su manutención sin escasez, manda a Lagos también todo el pan fresco que se pueda conseguir, y si hay algún dulce de Indias o de casa, mándaselo al comandante... Si hubiere algunos pichones puedes mandarlos también, pues sabes que en Lagos nada hay. Y también un par de arrobas de chocolate, y estar con cuidado por si el comandante vos escribiere para el destino de su tripulación y quisiere mandarla a Cádiz, fletarle todos los faluchos que necesitare para su transporte, avisándonos del precio en que vinieren fletados, tomando para esto todo el dinero que fuera ahí necesario y librarlo contra nosotros o pedirlo a Quintana en mi nombre mientras yo lo remito..." (Manuel Rivero a Juana Inocencio Cordero, 23 de agosto, 1759). Tan generosa asistencia granjeó a los Rivero oportunas intervenciones de los diplomáticos de Francia, realizadas en la Corte a su favor ${ }^{46}$, pero serían manifestaciones de la lógica no-económica (me refiero al egoísmo presunto del hombre liberal) de una cultura que premió el intercambio gracioso, de una sociedad firmemente asentada en el cruce de favores... lo que también fue la regla entre comerciantes honestos ${ }^{47}$.

${ }^{46}$ Pleguezuelo cit. (n. 31), p. 65.

${ }^{47}$ En línea con António Hespanha cit. (n. 3), ha tratado bien estas cuestiones Bartolomé Clavero, Antidora. Antropología católica de la economía moderna, Milano, Giuffrè, 1991. Abrió camino Karl Polanyi, La gran transformación. Crítica del liberalismo económico (1944), trad. Julia Varela - Fernando Álvarez Uría, Madrid, La Piqueta, 1989, pero la recuperación política del don y otros intercambios graciosos ha sido últimamente motivo de Jacques T. Godbout, Il linguaggio del dono (1996), trad.
No fueron ciertamente fenómenos al margen de los comportamientos cotidianos. "Ajustamos nuestras cuentas", advierte Lantery en referencia a un Antonio de Lima, "y me quedó debiendo diez mil y tantos pesos... como no tuvo forma de pagarlos y había experimentado su puntualidad... le dije que no le diese cuidado, que cuanto tenía estaba a su orden; ni quise que me hiciese escritura alguna, ni señalar premio, dejándolo todo a su arbitrio, porque me hice esta consideración: si tiene desgracia, todo se pierde, que haga escritura o no la haga; y si vuelve a salvamento, no solamente me pagará con sus premios, pero seré dueño de su caudal, porque su cariño y confianza era mucha conmigo (pp. 93-94). O también: "un dia me lo trajo a mi casa, con que fue fuerza recibirlo con civilidad, y tanto supo [un Justo de Lila] decir y hacer, que me sacó algunos doblones prestados, sin ningún género de interés más que el hacerle el gusto, porque me parecía que no los podía perder con un sujeto de esta calidad y con un mayorazgo tan grandioso, que en algún tiempo me podía ayudar a mí" (p. 42).Tan buena disposición hacia los menesterosos le obliga a pedir una espera de las propias deudas vencidas, y sus acreedores "vinieron en ello; que después pagué a todos sin pérdida alguna" (pp. 116117). La esperanza de una ayuda futura, el logro actual del cariño y la confianza eran razones más que suficientes, en conclusión, para conceder un crédito o renunciar a recoger

Alfredo Sasano, Torino, Bollati Boringhieri, 1998, y Alain Caillé, Il terzo paradigma. Antropologia filosofica del dono (1994), trad. Ada Cinato, ibd. 1998, ambos pertencecientes a la revista - movimiento - escuela identificado con el acrónimo MAUSS (Mouvement Antiutilitariste dans les sciences sociales). 
en escritura - esto es, a exigir judicialmente el pago - la deuda previamente contraida; al fin y al cabo, "il maggior guadagno, che debe procurar il Negotiante Christiano, debe essere di guadagnare la salute dell'anima con ben morire" 48 .

El motivo recién citado del préstamo a los grandes se rastrea con facilidad en la más antigua literatura destinada al público mercantil ${ }^{49}$, pero esa misma literatura, sensible como vemos a las expresiones de la gracia, nos informa además de nuevas derivaciones que encierran un mayor interés. Por ejemplo, en lo concerniente a las costumbres cambiarias.

El giro de letras de cambio movilizó como pocos negocios la cadena de amistades profesionales que ponía a prueba la solidaridad mercantil; de manera muy expresiva, los modelos documentales contenidos en la Lex Mercatoria de Malynes ("the nature of a Bill of Exchange is so noble and excelling all others dealings between Merchants, that the proceedings therein are extraordinary and singular, and not subject to any prescription by Law or otherwise; but meerely subsisting of a reverend custom, used and solemnized concerning the same", p. 269), esos mencionados modelos ofrecían cláusulas dirigidas "to my loving Friend Master W.C. Merchant at Amsterdam", "to my loving Friend Master G.M. Merchant at London Pa." (p. 270). Los usos que disciplinaban este

${ }^{48}$ Peri cit. (n. 22), Parte Quarta, p. 3.

49 Por ejemplo, Cristóbal de Villalón, Prouechoso tratado de cambios y contrartaciones de mercaderes y reprouacion de vsura, Valladolid 1564 (ed. facs. Valladolid, Universidad, 1945), cap.xvii, "en el qual se tratan cambios que se hazen con caualleros y señores", fol. xxvii ss. género de cartas comerciales, tan preñadas de sentido jurídico, admitían sin problemas la aceptación y el pago de efectos por terceros ajenos a la relación, en salvaguarda del honor de un colega o amigo del comercio aquejado de una dificultad momentánea; en el inglés de Gerard Malynes - siempre proclive a reproducir estereotipos documentales "another may accept the Bill for the honour of it... Which he doth in these Words, Accepted by me A.B. for the honour of the Bill" (p. 273). Y tanto en la ciudad de Londres ${ }^{50}$ como en el comercio con las Indias los gastos en banquetes y fiestas pudieron justificarse por ofrecer múltiples ocasiones a la práctica del apoyo recíproco, "no siendo extraño”, enseñaba Juan A. de los Heros en un texto más arriba recogido, "el que durante el tiempo de tomar una taza de café se haga una gran negociacion, se repare el crédito del librador de una letra, saliendo quien por su honor la pague ó se dirima una duda, cuya purificación costaria un pleyto". De intervenciones graciosas en la vida de la letra, residuo de la cultura del don que pasó al derecho moderno (cf. art. 526, Código de comercio de 1829; art. 511, Código de comercio de 1885), nos informa por su parte Raimundo de Lantery en un pasaje de las memorias donde combina perfectamente la amistad profesional con la obligada prudencia. Corría el año 1689. Un Francisco Polin paga

${ }^{50}$ Cf. Defoe cit. (n. 41), I, p. 358, donde la aceptación por honor (cuando "the correspondent happens to be dead, or is broke, or by some other accident the bill is not accepted... another merchant of the Exchange hearing of it, and knowing, and perhaps corresponding with the merchant abroad who drew the bill... accepts it, and pays it for him") se presenta como práctica del comercio internacional ("a case peculiar to foreign commerce... not often practised in home-trade"). 
varias letras que "había aceptado por honra de los dadores, que eran hombres muy conocidos suyos, de gran caudal y crédito", a pesar de lo cual se arruinó. "He querido poner este ejemplar aquí", precisa nuestro interlocutor saboyano, "para que los amigos que lo leyeren se guarden de emprender semejantes negociaciones, por ser muy peligrosas... aunque me contaron que don Pedro Colarte, con una negociación de éstas, se puso en boga, como dicen, por haber aceptado y pagado unas letras de unos de Nápoles, que no conocía más que por fama, le salió bien la cuenta y ganó muchos ducados después con ellos” (pp. 272-273).

"Para uno que sale bien, ciento se yerran”, concluía Lantery sentencioso. Sin embargo, los cien errados de su dicho fueron en la vida real otros tantos comerciantes ("los amigos que lo leyeren") que asumieron el deber de honrar un nombre reputado o de auxiliar comercialmente al colega en apuros; en el fondo, la buena fama financiera de la plaza donde todos trabajaban era un valor colectivo que convenía mantener. Por eso las costumbres locales fijaban los llamados precisamente - términos de gracia y cortesía para la presentación de efectos al pago o la aceptación ("the European merchants customarily allow a certain Time to the Acceptor after a Bill is due, which is call'd Time of Grace or Favour, which differs according to the customs of the Places drawn upon”); condescendencia final hacia el principal obligado cambiario ("it is so much law now itself, that no bill is protested now till those three days are expired") que tenía la función de hacer posible la intervención de los amigos o de poner en marcha los contactos necesarios para restañar un crédito mal andado ${ }^{51}$.

Una similar convicción llevó a considerar algo impropio de la profesión mercantil el liarse a pleitos y mezclarse con abogados y tribunales - incluidos, en los supuestos mejores, los propios jueces corporativos. "Por una porquería... no he de armar un pleito en la plaza, cuando hasta entonces no había tenido ninguno", anota con desdén Lantery al justificar el doble pago de 25 doblones por falta de prueba documental (p. 230). Más allá de los casos concretos, fácilmente localizables, el siempre locuaz Malynes describía en los cap. xiv ss. de Consuetudo, vel Lex Mercatoria (pp. 302 ss) hasta "four means to end Controversies" entre los comerciantes, esto es, según su mismo orden, tribunales marítimos (en Inglaterra, pero también en la Castilla medieval, "the great Admiral of the Seas"), árbitros elegidos por las partes, "merchant courts" o justicia consular ("according to the priviledges which Princes have granted to them") y, en fin, justicia ordinaria ("Jurisdiction of the several Dominions of Princes, according to the

51 The Universal Library cit. (n. 40), p. 13; cf. Defoe cit. (n. 41), I, p. 357, sobre los días de gracia ("those three days indeed are granted to all bills of exchange, not by law, but by the custom of trade; ' $t$ is hard to tell how this custom prevailed, or when it began, but it is one of those many instances which may be given, where custom of trade is equal to an established law; and it is so much law now itself, that no bill es protested now till those three days are expired ... no man offers to demand it, nor will any goldsmith, or even the Bank [of England] itself, pay a foreign bill sooner"). Para el caso español, las resistencias a una intervención regia en los usos profesionales, bastante flexibles en lo tocante al valor jurídico de la aceptación y, por ende, del protesto se desencadenaron con la fundación del Banco de San Carlos (1782): Petit, "Signos financieros" cit. (n. 27), pp. 302 ss. 
fundamental Laws of them"). Al margen ahora la debatida cuestión de la llamada recepción del Law merchant en los tribunales de Common law ${ }^{52}$, basta con resaltar que, de todas las instancias enunciadas, el arbitraje de algún colega ("by way of Arbitrement") constituía para Gerard Malynes la fórmula ideal: precisamente, "to avoid Suits in Law, which unto Merchants are inconvenient" (p. 303). Algo más tarde otro tratadista avanza en la misma dirección, al recomendar paciencia e incluso la aceptación pacífica de algún abuso... antes que ganarse fama de pleiteantes: "going to Law for a Debt, tho' the Debt be just, before all due and christian Measures are made use of to obtain Right by fair Means, that is, by peaceable Methods, is taking your Neighbour by the Throat, etc.., a Thing, tho' not expresly forbidden, yet left as an Example of ungrateful Fury and Rage, and a Mark of Infamy left on it" ${ }^{\text {53; }}$ llegado que fuera el caso de un pleito inevitable, siempre sería mejor un árbitro que un juez: "in other words, be always ready to put an End to such Prosecutions by Arbitrations where the Nature of the thing will allow them, and upon moderate Terms, where they will not, rather abating than rigorously exacting the utmost of your Demands" (p. 298). Y ciertamente, la predilección por el arbitraje

${ }^{52}$ Cf. James S. Rogers, "Orígenes del moderno derecho inglés de sociedades", en Petit (ed.), Del ius mercatorum al derecho mercantil cit. (n. 17), 307-332. Del mismo, The Early History of the Law of Bills and Notes. A Study of the Origins of Anglo-American Commercial Law, Cambridge, C. University Press, 1995.

${ }^{53}$ Defoe cit. (n. 41), II, p. 257; en general, cf. chap. xii, "Of the Tradesman's avoiding Law-Suits and Contention in Business, and studying to live peaceably with his Neighbours, especially in Matters of Trade", pp. 281 ss. pasó a la regulación corporativa, con cláusulas de obligada inclusión en los instrumentos de aquellos contratos con un riesgo elevado de provocar controversias; el supuesto, siempre complejo, de la sociedad de comercio ("porque al fin de las Compañías... se suelen suscitar entre los interesados de ellas muchas dudas y diferencias", reconocían las famosas Ordenanzas del Consulado de Bilbao, cap. $\left.10, \mathrm{n}^{\mathrm{o}} 6\right)$ fue al respecto prototípico ${ }^{54}$.

Los sentimientos de amistad entre mercaderes les aconsejaron rechazar pleitos, mantener relaciones epistolares, observar el amor y la gracia en el giro cambiario. Tales serían probablemente las enseñanzas de Manuel Rivero a sus hijos cuando los mandó a Nueva España, pero la carta donde les pedía "cumplir con Dios y el mayor adelantamiento de vuestro crédito, pues así me dareis todo gusto y redundará en vuestro mayor beneficio y ganar amigos del tamaño de esta casa" (8 de diciembre, 1750) contiene, junto al sentimiento de amistad que aquí nos ha interesado, un segundo concepto que también merece nuestro análisis. Pues los amigos mercantiles de los Rivero habían de ser tan grandes como ya podía serlo su $\operatorname{cas}^{55}$.

Me refiero al ganzes Haus brunneriano, entendido como ámbito social colocado bajo la autoridad omnímoda de un padre que además era el principal del negocio, a un tiempo complejo doméstico y empresa

${ }^{54}$ Cf. Petit, La compañía mercantil cit. (n. 9), pp. 250 ss, pp. 332 ss con edición de piezas documentales.

${ }^{55}$ Cf. Pleguezuelo cit. (n. 31), pp. 87 ss para la historia del noble edificio (1743-1744) costeado por Rivero, pronto conocido como la Casa Grande. Sin duda, aún lo es de Ayamonte. 
comercial $^{56}$. Ha sido desde luego el caso de Rivero, cuyos hijos podían escribir, al saber de un problema financiero, "que de este asunto y de cuantos ocurran debes dar noticia individual a padre, y sin pérdida de una hora, pues es padre y cabeza del cuerpo de la compañía" (carta de Cristóbal a José Antonio, 8 de mayo, 1770). Si bien se mira, los tratados utilizados contienen un variado repertorio de recetas para el gobierno de una casa donde los hijos de familia (lo mismo que los aprendices y otros empleados de confianza) ejercían de factores y escribientes... cuando no terminaban por asociarse al padre común; un compacto grupo humano unido por lazos de amor y sangre, pero también de convivencia profesional.

Desde sus comienzos la literatura económica - en el sentido etimológico de un término demasiado ambiguo - encontró referente y destino en las actividades cotidianas del jefe de una estirpe privilegiada y asentada en el aprovechamiento de explotaciones rurales, aunque no faltó alguna apertura hacia la ganancia comercial; de hecho, según un clásico del primer momento - los célebres Libri della famiglia de Leon Battista Alberti - la disciplina de la casa respondía a los valores y riquezas de una orgullosa dinastía de mercaderes ennoblecidos: "se voi considerate alquanto e discorrerete, riducendo a memoria quali siano esercizii accomodati a fare roba, voi gli troverete tutti posti non in altro che in comperare e vendere,

${ }^{56}$ Otto Brunner, "La casa grande y la oeconomica de la vieja Europa", en Nuevos caminos de la historia social y constitucional (1968), trad, Angel Francisco de Rodríguez, Buenos Aires, Alfa, 1976, 87-123. La proyección mercantil en Petit, "Mercatura y ius mercatorum" cit. (n. 17), pp. 30 ss. prestare e riscuotere" ${ }^{" 57}$. Se ha estimado que en los diálogos de Alberti “podemos encontrar ya todo lo que han dicho después en inglés Defoe y Benjamin Franklin”, pero hay que reconocer que cuanto esboza apenas el humanista florentino sólo logró desarrollo en obras posteriores ${ }^{58}$. Por esos años de Alberti un Benedetto Cottrugli, mercader dálmata de Ragusa (Duvronik) afincado en Italia, compuso un Libro dell'arte di mercatura que logró gran difusión en los siglos modernos (1573, 1582, 1602) - bajo el título, algo más expresivo, Della mercatura e del mercante perfetto $^{59}$. Y allí se consuma el cruce de lo estrictamente mercantil con los tópicos habituales del género doméstico. En efecto, el libro contiene mil consejos y orientaciones para la vida terrena del mercader, realizada entre los muros de su casa y sustentada en los negocios (cuyo régimen y particularidades se contemplan: cf. lib. I, con capítulos sobre compraventas, pago de débitos, cambios, depósito y prendas, seguros... y descripciones de ramos particulares de comercio: pañería, joyería, mercadeo de la lana), con el objetivo de alcanzar la vida eterna y de habitar otra mansión, que sería la sacra domus Dei. Pero la profesión del paterfamilias en una sociedad

57 Sobre Alberti, en general sobre el género indicado, cf. Daniela Frigo, Il padre di famiglia. Governo della casa e governo civile nella tradizione dell'economica tra Cinque e Seicento, Roma, Bulzoni, 1985.

${ }^{58}$ Cf. Werner Sombart, El burgués (1913), trad. María Pilar Lorenzo, Madrid, Alianza, 1979, pp. 116 ss. Ahora contamos con una colección de estudios, en particular de naturaleza bibliográfica, con Analysen (1470-1700) en el vol. III de Ars Mercatoria cit. (n. 12), Paderborn etc., Schöningh, 2001.

${ }^{59}$ Utlizo la excelente edición, con buen estudio preliminar, de Ugo Tucci, Venezia, Arsenale, 1990. Cf. Ars mercatoria cit. (n. 12), I, ref. C12.1-3, pp. 65-66. 
que cuestiona la productividad del dinero no dejaba de constituir un impedimento para acceder a la ansiada casa divina.

Por ahí comienza, entonces, la versión mercantil del gobierno doméstico. La obra que comentamos arranca de la creencia en un orden natural, impuesto por Dios con la creación, donde encaja a su vez la mercatura: ésta sería "arte o vero disciplina intra persone ligiptime giustamente ordinata in cose mercantili, per conservatione del'humana generation, con isperanza niente di meno di guadagno" (lib. I, cap. ii). La definición anterior es elocuente, pues si cabe una esperanza de ganancia, ello se debe a imperativos de conservación del género humano: el lucro sólo resulta legítimo si obedece al designio con que "l'omnipotente Idio nella criatione del modo ordinò tucte le cose con le conditioni loro naturali" (lib. I, cap. i). La idea de orden - tan acertadamente propuesta no hace mucho para dar cuenta de la cultura jurídica de antiguo régimen ${ }^{60}-$ justifica la naturalidad del comercio ("per necessità delle cose che mancavano a uno et superhabundavano ad altro", lib. I, cap. ii) pero también palpita en algunas técnicas características de la profesión, como la teneduría de libros y las reglas de contabilidad (cf. "Del'ordine di tenere le scripture", cap. xiii), lo mismo que, más generalmente, en la conducción del tráfico (cf. lib. I, cap. x, "Modo et ordine universale di trafficare") y el regimiento de la casa mercantil.

${ }^{60}$ Paolo Grossi, L'ordine giuridico medievale, RomaBari, Laterza, 1995, con inmediata traducción (cf. El orden jurídico medieval, trad. Francisco Tomás y Valiente Clara Alvarez, Madrid, Marcial Pons, 1996).
El texto de Cottrugli resulta en este punto muy expresivo. Su libro cuarto ("Della vita economica"), repleto de advertencias sobre la elección de esposa ("usa moderatamente il coito, et con paucità", cap. v) o el uso y color de los vestidos (con preferencia oscuros, "significativi di gravità e senno... ma guardati di vestire di seta", cap. iv), contempla en especial la actividad económica de un destinatario que, al ser mercader, tiene que disponer de espacios para escritorio y almacenes (cap. i, donde se aconseja además al pater "che si dilecta di lectere... havere scriptoio separato") y debe combinar los negocios con otras inversiones menos azarosas: "perchè non sa li casi della fortuna che pottrebero advenire", el perfecto comerciante "debbe trarre alcuna parte del guadagno et investire in cose stabili" (lib. IV, proemio), esto es, tierras de producción y recreo y casas de habitación; la destinada al uso propio conviene esté situada cerca de los lugares habituales de encuentro y negociación ("in loco piano et propinquo a luogo di negotiatione et ricepto de mercanti”, cap. i), adornada con la prestancia que exige la imagen pública del comerciante (“de’ havere onorato introito per li forestieri che non li cognoscono se non per fama, et molto t'atribuisce bella presentia et residentia di casa", ibd.). Sin embargo, el capítulo destinado a mayor fortuna - aborda una cuestión que suelen incluir las obras posteriores - se refiere a la educación de los hijos ("De figliuoli", lib. IV, cap. vii). Son páginas donde la temática económica se hace directamente mercantil, ya que esos hijos que se recomienda criar con la leche materna (o al menos de una ama que fuera hermosa y sana, "perché eredano molto li figliuoli dalla latte") y 
someter a intermitentes y calculadas privaciones ("per consolidare la natura in robustità") serían unos mercaderes en embrión que deben aprender gramática y retórica y, desde luego, con la práctica y el ejemplo del padre, el difícil arte del comercio; se advierte en especial sobre la conveniencia de inculcarles un buen uso del dinero ("fa che al tuo figliuolo non lasci maneggiare danari fino che cognoscha che cosa è il danaro et quanto vale, et con quanta fatica si guadagna"), a cuyo fin puede ser útil el sufrir algún fracaso financiero, "perchè [el joven desengañado] conprehende la difficultà del guadagnare et studia cerca l'industria", en vez de volverse "temerario et presumptuoso, in modo che poi fa molti disavanzi”.

No sería difícil alegar otros ejemplos de la sensibilidad pedagógica localizada en nuestros tratados de mercatura ${ }^{61}$. En general,

${ }^{61}$ El lector sabrá disculpar la inclusión en esta nota de un párrafo algo prolijo pero muy eficaz en el sentido alegado, pues contiene la metodología de composición del tratado famosísimo (más de treinta ediciones, llegando al siglo XIX) de Jacques Savary. Situado en apertura de Le Parfait Négociant, I, cit. (n. 13), reza como sigue: "J'ay cherché une méthode dont la suite heureuse \& naturelle pust rendre l'ouvrage plus agréable $\&$ entre plus aisément dans l'esprit \& et la mémoire des jeunes gens qui voudront s'instruire \& embrasser la profession mercantille. Pour cet effet je prens au sortir de ses père et mère, \& començant de l'instruire dès son apprentissage, je le mène ensuite dans la vente des Marchandises en détail, dans le Gros, dans le Change, dans les Manufactures, dans les Foires: je le conduis mesme dans tous les Pais Estrangers, \& jusques dans les lieux les plus eloignéz par les voyages de long cours, \& en le menant ainsi, je luy fais voir toutes les maximes qu'il doit observer; les choses qu'il doit éviter; \& je luy fais connaitre mesme à fur et à mesure que cela se présente, tout ce qui peut regarder quelque sorte de Commerce \& de Négoce que ce soit, directement ou indirectement, jusqu'aux moindres circonstances, avec l'application des Ordonnaces Royales, \& et surtout de l'Ordonnance du mois de mars 1673, afin qu'il puisse se conduire heureusement dans cette professions si utile con mayor precisión que el vetusto libro de Cottrugli - apenas un precedente medieval - a finales del antiguo régimen se entendía de manera pacífica que "pour qu'un marchand soit reputé véritablement habile homme, et capable d'entreprendre et de faire toute sorte de commerce soit de terre soit de mer, il doit savoir plusiers choses", a saber, el índice de materias de cualquiera de los textos hasta aquí examinados $^{62}$. Ahora bien, antes que repetir tales saberes en una monótona letanía (ya se vieron: escritura, aritmética, contabilidad, lenguas, redacción de contratos, monedas, pesos y medidas, geografía comercial...) parece suficiente recordar un par entre los muchos títulos que presentaron las doctrinas y prácticas del comercio como el curriculum ideal que el padre-mercader había de transmitir a los miembros más jóvenes de la casa.

Por ejemplo, un Matteo Mainardi compone en el siglo XVII L'economo, overo la Scrittura tutelare, una suma de contabilidad "conforme è lo stile Mercantile" presentada bajo la excusa de administrar el caudal hereditario qur toca a unos hermanos, sometidos a tutela; la profesión del hipotético causante aparece muy clara en la predilección de esas páginas por el complicado cálculo de los cambios ${ }^{63}$. Un siglo después se difunden

et si honorable". Como vemos, de la cuna a la Ordonnance la educación de un joven marchand es el motivo literario que se sigue para exponer la ciencia y los valores culturales del comercio y de sus gentes.

${ }^{62} \mathrm{Cf}$. Encyclopédie méthodique. Commerce cit. (n. 14), s.v. "Marchand", pp. 69-70.

${ }^{63}$ Matteo Mainardi, L'economo, overo la Scrittura tutelare; scrittura mercantile formalmente regolata, con le Lettere de' Negotij à quella correlative. Il cambio reale per ogni piazza. Giustamente ragguagliato, con diversi altri Quesiti utili, curiosi, e necessarij alla Mercatura, Bologna, per il Longhi, 1700. Cf. Ars mercatoria cit. (n. 12), II, ref. M2.1-6, pp. 346-347. 
unas Lettres d'un négociant a son fils, sur les sujets les plus importants du commerce, donde la forma epistolar - en tanto circuito de comunicación que funciona ahora entre un padre y su hijo - ha servido de estrategia educativa ("que nous présentons aux jeunes élèves du commerce") pero también de objeto principal de formación ${ }^{64}$. Y, como sabemos, las cartas familiares fueron el recurso seguido por Daniel Defoe para impartir reglas de vida y profesión al incipiente tradesman ${ }^{65}$.

La superación de la etapa educativa del joven mercader no tenía por qué suponer un abandono de la casa para negociar de forma autónoma. Aprovechando que la potestad paterna sobre los hijos se extendía sin muchas concesiones al transcurso del tiempo, ciertas instituciones mercantiles convirtieron la dependencia doméstica en una excelente estrategia comercial. Tal ha sido, sin duda, la misión histórica del contrato de compañía, auténtico nudo jurídico que sirvió para vincular la convivencia familiar al ejercicio en común del comercio. Sin salir de los ejemplos antes examinados, sabemos que Manuel Rivero, tras una primera experiencia de asociación con varios colegas ingleses (1742), formó compañía de comercio con su hermano Cristóbal entre 1742 y 1753 y, aún ésta vigente, otra con sus hijos José Antonio

${ }^{64}$ Lettres d'un négociant... Précédées d'Observations sur la manière d'écrire les Lettres de Commerce, de rédiger les Contrats, les lettres de Change, les Obligations, Garanties, Procurations, Accords, \& autres pièces reltives aux affaires du Commerce, Strasbourg, Armand Koenig, 1789.

${ }^{65}$ Cf. Otho Clinton Williams Jr., A Study of Daniel Defoe's The Complete English Tradesman, as a Preliminary to a Critical and Definitive Edition, diss. Ph. D. (English), University of California, 1950, pp. 128 ss sobre la impronta epistolar utilizada. y Manuel, bajo la firma de "Manuel Rivero e Hijos" (1749); la supremacía del padre aparece en la mayor cuota de ganancias y pérdidas que le tocaba, así como en el siempre duro alejamiento de los socios-hijos de Andalucía al continente americano. Cuando se renueva esta sociedad en 1751 se suma un Antonio Trianes, casado con la hija y hermana Teresa; ahora se acuerda el reparto igualitario de las cuotas entre los socios, pero sólo el viejo Rivero conserva el derecho de negociar por propia cuenta. De todas formas, una cierta decadencia de sus amplios poderes directivos - acaso reflejo de la debilidad física que acarrean los años - se aprecia en las renovaciones sucesivas de la compañía, mediante contratos $(1756,1760,1765)$ que cercenan la facultad paterna de incorporar libremente nuevos asociados a la empresa e imponen un mayor control sobre los dineros comunes ${ }^{66}$.

Los usos de la saga onubense coincidieron con los seguidos entre comerciantes de cualquier otra plaza. En realidad, la naturaleza del contrato de sociedad - un pacto concluido intuitu personarum - participaba de la lógica del grupo familiar, continuamente invocado como el cauce institucional más útil para las de comercio: en el recio castellano de las Partidas, la compañía (lo mismo casi que el matrimonio) era definida como "ayuntamiento de dos omes, o de mas, que es fecho con entencion de ganar algo de so uno, ayuntándose los unos con los otros... ca se acorren los unos a los otros, bien assi como si fuessen

${ }^{66}$ Para todo esto, Pleguezuelo cit. (n. 31), pp. 44 ss. El desvío de cuantiosos fondos hacia las empresas edilicias y las inversiones en tierras de Rivero fue un constante motivo de queja por parte de los hijos. 
hermanos" (p. 5,10,1). Y aunque la mercantil se establecía por lo común a término, su vida perduraba tan sólo mientras existía una dicha affectio societatis ("voluntad de fincar en ella", traducen las Partidas - p. 5,10,11); merece la pena observar que affectio es una expresión preferida, con toda intención, al término habitual en el derecho de contratos para identificar la voluntad negocial (esto es, consensus), pues se usó por la doctrina “en el mismo o análogo sentido que se la emplea en el matrimonio"67.

Al estudiar la práctica de Bilbao durante la vigencia de sus famosas ordenanzas consulares pude comprobar que la gran mayoría de las sociedades constituidas entre 1737 y 1829 se celebraron entre miembros de una misma casa, produciéndose entonces una cierta confusión entre las instituciones familiares y las propiamente mercantiles ${ }^{68}$. Por ejemplo, en el contrato matrimonial otorgado en 1751 por Lorenzo de Landázuri y María Josefa de Bekvelt y Croce se estipula,

${ }^{67}$ Cf. Martínez Gijón cit. (n. 29), pp. 386-387, pp. 389 ss (esto es, J.M.G., La compañía mercantil en Castilla hasta las Ordenanzas del Consulado de Bilbao de 1737. Legislación y doctrina, Sevilla, Publicaciones de la Universidad, 1979, p. 64, pp. 67 ss). Con posterioridad, vid. Umberto Santarelli, Mercanti e società tra mercanti, Torino, Giapicchelli, 1992, centrado en la experiencia medieval y con un excelente desarrollo de la conexión familia - sociedad de comercio.

${ }^{68}$ Conviene advertir que la superposición de los lazos de parentesco y la condición de asociado no agotó todas las posibilidades; así, en el contrato de Juan Matías y Joaquín Sarachaga (Sarachaga Hermanos, 1743) el capital procedía de la madre Antonia Francisca de Santacoloma, ante la que se declaran obligados pero sin constituirla en socia capitalista. Cf. Archivo Histórico Provincial de Vizcaya (AHPV), protocolo de Joaquín de la Concha, leg. 3327, fols. $743-748$ v, 9 de noviembre, 1743; ed. Petit, La compañía mercantil cit. (n. 9), apéndice en pp. 275-278. además de la entrega de ciertas alhajas, el pago de catorce mil ducados en concepto de dote "que han de quedar efectivos en poder de... sus padres y suegros respective... para que resulte en mayor beneficio de la compañía que manejan", pero los padres de la esposa "se obligan en debida forma a dar y entregar a los dichos señores su yerno e hija, la octava parte de todas las ganancias de los negocios y cosas que emprendieren y tuvieren de cualquier género y naturaleza que sean... en la compañía de comercio y negociación que siguen y tienen formada con el Sr. D. Pedro Javier de Bekvelt y Croce, su hijo"69. De manera aún más explícita la escritura matrimonial de Francisco de Gallaga y Joaquina Manuela de Smith y Weldon, treinta años posterior, contenía una fórmula parecida en lo tocante a la dote, pero constituía a Gallaga en la obligación de entrar en sociedad con los suegros, fijándose a continuación las cláusulas principales de ese segundo contrato $^{70}$. Sin duda muchos de estos hijos políticos de los comerciantes bilbainos serían antiguos empleados de la casa, educados en ella por el principal $^{71}$; lo fueran o no, la posibilidad de asociarse con factores y dependientes - a falta de capital aportaban su

${ }^{69}$ AHPV, Joaquín de la Concha, leg. 3335, fols. $458 v^{\circ}-459 v^{\circ} .26$ de diciembre, 1751. Cf. contrato de Pedro de Beckvelt e Hijo, ibd., leg. 3341, fols. 219222 $\mathrm{v}^{\mathrm{o}}, 8$ de junio, 1757.

70 AHPV, Martín Antonio de Arrien, leg. 2787, 13 de mayo, 1781. La posición de Gallaga estaba bastante degradada, pues el contrato deja sólo en manos de sus suegros la opción de renovar la compañía, prevista por diez años.

${ }^{71}$ Por ejemplo, Rita de Alegría se asoció con su yerno Bartolomé de Echevarría, factor que había sido de su difunto marido, José de Yzarduy. AHPV, Carlos de Achútegui, leg. 2706, fols. 158 - 163, 1 de marzo, 1768. 
trabajo y experiencia, algo frecuente en la práctica y aceptado por la regulación gremial (cf. Ordenanzas de Bilbao, cap. x, no 14) nada tuvo de extraordinario ${ }^{72}$.

Parentesco y colaboración estrecha eran la causa de una intimidad entre los socios que acentuaba el génerico amor o la amistad característicos entre los colegas del comercio ("la premiere chose que doivent avoir deux Associés, est l'amitié \& et la déférence l'un pour l'autre, car c'est d'où dépend tout le bonheur ou la malheur de leurs affaires communes", advertía con razón Savary ${ }^{73}$; por eso, en un nuevo encuentro de lo familiar y lo jurídico-mercantil aquéllos podían designarse recíprocamente albaceas testamentarios $^{74} \mathrm{o}$ incluir en el contrato de compañía la concesión, también recíproca, de poderes para testar ${ }^{75}$. Más habituales

72 Así, un Francisco Pérez de la Mata, "deseando premiar al nominado don Miguel [Vítores], dependiente suyo hace muchísimos años, y atendiendo al mérito y servicios leales, con una prueba segura y apreciable de su confianza, ha venido en asociarle a sus negocios", leemos en el contrato de la Viuda de Mata e Hijo, AHPV, Pío de Basabé, leg. 3.244, fols. 528 - 532, 28 de septiembre, 1793.

${ }^{73}$ Le Parfait Négociant cit. (n. 13), I, chap. iv, p. 386. Cf. ibd. p. 388, donde se considera que entre las "ressources pour trouver de l'argent" al alcance del socio responsable de la caja "la plus grande ressource est celle des amis particuliers qui sont puissans en argent, qui n'en refusent pas quand ils y trouvent leur sureté".

${ }^{74}$ Contrato de compañía de Grossman y Bauch, 1 de enero, 1758. En Archivo del Consulado de Bilbao, caja 15 , reg. $1, \mathrm{n}^{\circ} 41$.

75 "Mediante tener comunicadas nuestras cosas y voluntad respectiva, nos, los dichos... otorgantes, en la vía y modo que más haya lugar, damos por esta escritura amplio poder recíproco uno a otro, insolidum y en toda forma, para hacer por el que muera de nosotros su testamento, cualquiera que de nos sobreviva, y elegir convento, iglesia y sepultura, disponer el entierro, funerales, sufragios y su estipendio, señalar mandas fueron, con todo, los pactos para compartir casa y gastos; al fin y al cabo, en virtud de esta relación comercial quienes no estaban unidos por la sangre convivían como familia según lo anunciado en las Partidas: la etimología del vocablo compañía remite, como es sabido, al deseo de compartir un mismo pan. Y así, al asociarse Linch y Killi Kelly en el Bilbao de 1736 acordaron "que la renta de la casa en que habitan y habitaren, lonjas, entresuelo, todos los alimentos y gastos de la casa y salarios de los oficiales, criados y criadas necesarios para el servicio de esta compañía, se ha de pagar de las ganancias que hubiere en los negocios, comisiones y empleos de esta compañía"76. En buena lógica, muchas de las veces en que la sociedad era pactada entre el padre y los hijos, el primero corría con los gastos de la casa común ${ }^{77}$.

pías y graciosas, nombrar heredero o herederos como y cuando les plazca...", escritura de Francisco y Juan Cristóbal Krause y Compañía, AHPV, Bruno de Yurrebaso, leg. 4006, fols. 217 - $221 \mathrm{v}^{\mathrm{o}}$. $22 \mathrm{de}$ marzo, 1762.

${ }^{76}$ AHPV, Manuel de Bolívar, leg. 3163, sin foliar, 1 de mayo, 1736.

77 Por ejemplo, en el caso de José de Gardoqui e Hijo, "ha de ser de cuenta y cargo de dicho don José [el padre]... durante los expresados dos años, el gasto diario de la casa, su renta y lonja... en que habitan y todas las demás que se arrendaren para la negociación y comercio de dicha compañía, sin que a cosa ni parte de los referidos tenga obligación dicho don José Joaquín su hijo de contribuir con maravedí alguno"; el padre se reservaba un tanto al efecto, pero habría de pagar de su bolsillo si los gastos domésticos se disparaban. AHPV, Joaquín de la Concha, leg. 3340, fols. $568-571$ v $^{\mathrm{o}}, 4$ de octubre, 1756. Tal sería la fórmula, entiendo, cuando se prevé que sólo el paterfamilias pueda sacar del fondo de la compañía una asignación para cubrir los gastos familiares: cf. Laurencín e Hijo, AHPV, Antonio Agustín de Quintana, leg. 4539, fols. 908 - $910 \mathrm{v}^{\mathrm{o}}, 17 \mathrm{de}$ septiembre, 1793. 
La contrapartida de la mayor responsabilidad paterna se traducía en la desigualdad de las cuotas de participación y en el peso del 'principal' en la dirección de los negocios sociales, mediante cláusulas que venían a reproducir las dependencias familiares en términos muy parecidos a los pactados por los Rivero ${ }^{78}$. Hemos visto más arriba a yernos de poca fortuna que pasaron a colaborar con sus suegros desde una posición filial; pues bien, los contratos de Bilbao nos presentan aún a socios-factores y socios-hijos no autorizados - justo al contrario que el paterfamilias - para granjear por su propia cuenta, o que sólo podrían hacerlo cuando lo consentía expresamente la "persona mayor de la compañía"; en los términos del contrato de Goosens e Hijo, "la dirección de los negocios correrá bajo el cuidado de ambos, pero siempre con sumisión a lo que determinare dicho don Juan Enrique Goosens, sin que el dicho don Enrique Alejo su hijo pueda emprender negocio alguno sin su consentimiento"79. Se trata de una muestra de sumisión entre muchas ${ }^{80}$, casi tantas

78 La dirección no suponía, claro está, el trabajo material de gestión. En la compañía antes mencionada de Rita de Alegría y Bartolomé de Echavarría este socio "ha de asistir de continuo a llevar el peso del comercio y escritorio, como hasta ahora lo ha hecho, y las ventas y compras de géneros, aceptar letras y librarlas en cabeza de dicha Doña Rita de Alegría, y con poder suyo percibir, cobrar y pagar, para lo cual le da y confiere... el necesario y cual derecho se requiere, como para todo lo demás que se ofrezca con motivo de dicho comercio, y para quitas, esperas, ajustes y convenios que acontecieren como acreedores o deudores de resulta de dicha compañía...", a tenor del contrato (1768) cit. (n. 71).

79 AHPV, José de Aranzazugoitia, leg. 2633, fols. 150 - 153 vo, 8 de marzo, 1776. Cf. Petit, La compañía mercantil cit. (n. 9), pp. 145 ss.

80 He aquí una más, ejemplo de exigencias paternas desde la otra vida. Al otorgar testamento Domingo Killi como contratos de sociedad fueron celebrados entre parientes.

La religión de los mercaderes se convirtió en devoción y amistad; la amistad favoreció el tráfico de cartas, en particular de letras de cambio - un instrumento financiero muy sensible a los deberes honorables de la común profesión. Aquélla mercantil se entendía además tan honrosa que debía huir de pleitos... gracias a los buenos oficios de colegas que arbitrasen las diferencias surgidas en los momentos peores. Cartas, amigos, letras, arbitrajes... en fin, llevados desde una casa que fue ante todo familia, con el contrato de compañía para refuerzo de los vínculos consanguíneos.

Tal vez cualquier lector, a la vista de este o ese otro documento, matice y refute fácilmente la anterior descripción. Pues qué, ¿nunca se dieron pleitos entre comerciantes que hubiera de zanjar una autoridad judicial? ¿El apetito de lucro no condujo jamás a exprimir a los deudores sin contemplación alguna? La historia de la cambial, ¿no marchó a favor de la fuerza ejecutiva de compromisos de pago que no admitían demasiadas reticencias? La respuesta afirmativa a todas estas objeciones me parece compatible con el propósito actual de identificar los valores, usos y comportamientos - en una palabra, el tejido de costumbres en el sentido inicialmente recogido - de la vieja clase mercantil, al

Kelly ordenó que sus hijos y yernos continuasen los negocios asociados y "para que haya la debida claridad y el que se sepa su capital, otorguen escritura de compañía, entrando en ella lo que a cada uno le corresponde de legítimas". AHPV, Blas Joaquín de Lazcano, leg. 5585, sin foliar. 
menos cuando la intención de la lectura que está a punto de acabar se limita a descifrar las claves de la auto-representación, de la imagen profesional que un clásico mercader se formó de sí mismo y sus colegas. Nada contaría entonces un contrato social donde se reconociera al hijo facultades especiales que los más atribuían al padre o demostrar la existencia histórica de negociantes encallecidos que nunca dieron tregua a sus deudores. Mantengo mi convicción de que, hasta en esos supuestos contrarios al relato que ahora finaliza, la vieja cultura mercantil aceptó con toda naturalidad la existencia de familias mutadas en sociedades de comercio o la vigencia de la moral y la gracia en el terreno jurídico de las obligaciones, con inclusión por supuesto de las exigentes obligaciones cambiarias.

Si se comparte tal convicción, en un segundo paso interpretativo hemos de concluir que la cuestión del usus mercatorum con que arrancaba nuestra encuesta no sería demasiado relevante para trazar los orígenes del moderno derecho mercantil. Los datos examinados nos conducen hacia una amalgama de normas y creencias religiosas, imperativos profesionales, directrices para el gobierno de la casa, compromisos de amistad, códigos de honor... que ofrecen un paisaje demasiado exótico para explicar sin más el ordenamiento especial del comercio a partir de antiguas ordenanzas y prácicas institucionales (sociedades personalistas, letras de cambio, auxiliares del comerciante, libros de contabilidad, reglas para el caso de insolvencia...) poco menos que inalterables. Que los órdenes normativos y los principios implicados - un derecho gremial ciertamente, aunque colocado junto o incluso por debajo de la economía o ciencia doméstica, la moral, en particular aquélla católica y postridentina, el mismo saber mercantil, con su notable carga disciplinante de la vida profesional y el escritorio - carezcan hoy de relevancia explicaría las limitaciones de una difundida historiografía, pero se trata de superar este empobrecido horizonte si queremos comprender una cultura que no es la nuestra ${ }^{81}$.

Se encuentra además en debate la correcta identificación de la experiencia jurídica presente. Si el derecho mercantil ha sido el único ordenamiento corporativo que subsistió al momento revolucionario, si ese instante irrepetible constituye el inicio del fin del antiguo régimen también en materia de contratos, en tal caso subsistiría el problema de trazar con precisión las fronteras de la modernidad. Darnos por satisfechos con describir la estrategia burguesa de conservación del propio derecho sobre la base del protagonismo histórico de que gozó el tercer estado resultaría una banalidad, situada a un paso de la más clamorosa pseudoexplicación. Expresado de otra forma: a cuantos leimos en los Setenta la síntesis feliz de Francesco Galgano, treinta años más tarde la interpretación del conocido privatista de Bolonia aun disfrazada editorialmente bajo un título nuevo y equívoco - nos parece un análisis demasiado pobre ${ }^{82}$.

${ }^{81}$ Otra vez me baso en lo que escribí a propósito de "Mercatura y ius mercatorum" cit. (n. 17), pp. 68ss.

${ }^{82}$ Francesco Galgano, Storia del diritto commerciale, Bologna, Il Mulino, 1976, en su elementalidad aún suscrito íntegramente por el autor bajo el título Lex Mercatoria. Storia del diritto commerciale, 1993, nueva ed. 2001. Por otra parte, Galgano ha permanecido ajeno 
¿Habrá que renunciar a la explicación política de una justicia y un derecho especial para el comercio? Digamos mejor que el futuro debate tendría que centrarse en el alcance reconocido a la posible continuidad. Pues acaso sea tan sólo aparente la existente entre un viejo consulado y un tribunal liberal - por más que ambas instituciones conocieran de asuntos similares. Tampoco debería alcanzar mucho peso la existencia de una codificación separada para el derecho del comercio. En realidad, la aparición del derecho mercantil exigió una previa, gran tarea expropiatoria sobre el universo tradicional de costumbres, cortesías y usos; una drástica supresión de los diversos y simultáneos órdenes normativos que regularon históricamente negocios y negociantes... a beneficio exclusivo del Estado y de su único orden de normas, un nuevo orden solamente jurídico. Por efecto de los códigos liberales me refiero ahora al contexto que les dio sentido - la disciplina del comercio se redujo a ley, la ciencia doméstica fue economía política, la religión y sus secuelas graciosas, una simple opción privada sin relevancia profesional. Y los lazos de parentesco y amistad, esenciales en la antigua casa de comercio, se vieron paulatinamente relajados hasta su completa superación... mediante sociedades tan anónimas en el trato con terceros como lo serían en las hipotéticas

a la incesante aportación historiográfica (sin salir de la academia italiana: Birocchi, Migliorino, Piergiovanni, Santarelli, Savelli...), algo que, más allá de motivar un juicio severo acerca de su rigor de estudioso, llevaría a una interesante reflexión sobre la circulación de resultados y discursos entre especialidades tan próximas como diferentes. relaciones que mantuviesen sus socios; sin duda tendría interés escribir una pequeña historia de la preferencia relativa de los comerciantes por cláusulas nominativas o por cláusulas a la orden en acciones y demás títulos valores.

Con los cambios en la mentalidad mercantil de la gracia, la amistad, la affectio, el intuitus personarum... se extinguió aquel pujante género de mercatura que convirtió en texto impreso los referentes tradicionales de la profesión y facilitó su reproducción continuada. Por supuesto, a lo largo del siglo XIX aún podía aparecer una flamante Biblioteca del comerciante, pero se trataba exactamente de unos Elementos del derecho mercantil español ${ }^{83}$. Todavía había espacio para un Tratado elemental, teórico-práctico de relaciones comerciales dotado de tablas, cuadros y nociones según cuanto contenían los manuales de siglos anteriores, aunque el subtítulo de ese otro dejaba las cosas en su sitio: la materia mercantil se ofrecía conforme a lo prevenido en el Código de comercio ${ }^{84}$. No me parece casual que la antigua educación comercial, desarrollada en el seno de la familia y servida por aquellos manuales, pasara tras los códigos a centros de nuevo cuño, pertenecientes al Estado ${ }^{85}$.

${ }^{83}$ Damián Sogravo y Graibe, Elementos del derecho mercantil español, o Biblioteca del comerciante, Madrid, P. Madoz y L. Sagasti, 1846.

${ }^{84}$ Gerónimo Ferrer y Valls, Tratado... Madrid, Tomás Jordán, 1833.

${ }^{85}$ Cf. Paola Massa Piergiovanni (cur.), Dalla Scuola Superiore di Commercio alla Facoltà di Economia... Genova, Società Ligure di Storia Patria, 1992; de la misma, "Tra tecnica e cultura: l'istruzione superiore commerciale nella seconda metà dell'Ottocento", en 
¿Se perdió así, con ese Estado legal y docente, la eficacia práctica del uso comercial? ¿No teníamos por el contrario entendido que el espacio reservado a la costumbre entre las fuentes del derecho del comercio es una razón principal que justifica su especialidad ${ }^{86}$ Otra vez nos inclinamos por admitir una sencilla respuesta afirmativa que, sin embargo, también asume y reconoce la transformación que encierra el entendimiento puramente jurídico de la antigua costumbre mercantil.

Ruego a mis lectores un tributo final de paciencia que me consienta alegar en mi causa dos textos aparecidos en el siglo XIX, engendrados por lo tanto desde el paradigma liberal. Manuales referidos al comercio, ahora sus destinatarios son juristas en ciernes, que estudian en facultades de Derecho una materia particular. Cuando los planes universitarios (españoles) aún la aproximaban al Derecho Penal - derivación, sin duda curiosa, a partir de la común expresión codificada - la flamante asignatura de Derecho Mercantil había de cursarse sobre títulos improvisados - apenas un comentario somero del viejo Código de comercio (1829). Y uno de los más difundidos, a juzgar por sus varias ediciones, fueron las Instituciones del Derecho Mercantil de España (1848) de Ramón Martí de Eixalá (1808-1859).

La versión que consultamos es edición revisada (1865) por Manuel Durán y Bas, un

Dalla Scuola Superiore di Commercio alla Facoltà di Economia. Atti del convegno Genova, 27 novembre 1992, [Genova], Ecig, [1992], 13-24.

${ }^{86}$ Cf. Joaquín Garrigues, Curso de Derecho mercntil, I (rev. A. Bercovitz), Madrid 19767, p. 122: "la formación del Derecho mercantil como una desviación especial del Derecho civil explica la importancia del uso". conocido hombre público, sucesor de Martí en la cátedra de Barcelona ${ }^{87}$; a él se debe por entero, entre otros retoques que no nos interesan, un capítulo inicial "de la naturaleza del fenómeno comercio con relación al derecho" (pp. 2 ss). Me parece un testimonio significativo de los cambios acontecidos el empleo por Durán y Bas de motivos textuales viejísimos, utilizados sin embargo con muy diversa argumentación. En efecto, quienes no hayan olvidado los pasajes antes citados de Benedetto Cottrugli y Gerard Malynes apreciarán las similitudes que aproximan, pero también las diferencias que separan el Libro dell'arte di mercatura y la Lex Mercatoria del manual catalán de Derecho Mercantil. "El origen racional del comercio se encuentra en la desigualdad de condiciones de los hombres y de los pueblos", enseña por ejemplo Durán (p. 8), con una sencilla explicación 'laica' - más precisamente: racional - allí donde Cottrugli se remitía a la voluntad divina ("l'omnipotente Idio nella criatione del modo ordinò tucte le cose con le conditioni loro naturali”). Igualmente laico me resulta el pensamiento que recorre el artículo destinado al "orígen histórico del comercio", pues si el católico profesor de Barcelona se remonta a "la historia de Egipto en tiempo de los Faraones y la de Roma antes de nuestra éra" (p. 9), por el contrario jamás le entretiene la historia sagrada de los Abrahames y los castos Josés, los banqueros metidos a evangelistas y los pescadores-papas que sirvió antiguamente para dignificar una actividad profesional comprometida; como

87 Ramón Martí de Eixala, Instituciones... Cuarta edición notablemente adicionada por D. Manuel Durán y Bas, Barcelona, Librería de Alvaro Verdaguer... 1865. 
mucho, la narración histórica de Durán demostraría la necesidad universal del comercio y las razones que justifican reservarle en los tiempos modernos un tratamiento jurídico singular. $\mathrm{Y}$ en vez de la vocación apostólica de los mercaderes más viajeros, portadores de la fe cristiana en tierras alejadas de Europa (Lessenius), nos encontramos una descripción del comercio en tanto "fenómeno [que] supone siempre la relación inmediata del hombre con el hombre; y esta relación proviene, no solo del contacto en que el ser inteligente y libre se encuentra con las cosas ú objetos que componen la naturaleza no libre que le rodea, sino de los recíprocos servicios que para obtenerlas se prestan los hombres, no generosamente sino movidos por su particular interés" (p. 12).

No generosamente, sino movidos por interés particular. Dejemos en este punto importante la obra escolar de Martí-Durán para observar la doctrina de los usos según otro escrito, igualmente destinado al público universitario. Me refiero al Tratatto di Diritto Commerciale del italiano Cesare Vivante ${ }^{88}$, cuyo primer volumen se ocupa de las costumbres mercantiles... pero siempre en el sentido culturalmente limitado de unas "norme di diritto costituite mediante l'osservanza giuridica dei mercanti' (p. 44). Fuente supletoria, último recurso antes de desencadenar la aplicación del derecho civil común en un asunto de comercio, las costumbres que presenta Vivante sólo son normas de derecho penetradas de la economía política y la ley codificada (un auténtico sistema de "leggi commerciali, che

${ }^{88}$ Cesare Vivante, Trattato... Torino, Fratelli Bocca, 1893. contengono gli usi generali consacrati dal legislatore", p. 47). "Perciò non contribuiscono alla formazione di un uso gli atti di mera tolleranza, di liberalità, di condiscendenza che non si compiono coll'intenzione di riconoscere un diritto altrui", enseña aún el famoso privatista, "come tutti gli abbuoni, le dilazioni, i favori conceduti alla propria clientela" (p. 46). Vivante refuerza su descripción con una larga muestra de actos que no engendrarían un uso al no ser de obligado cumplimiento (" $\mathrm{i}$ doni inviati pel capo d'anno, i ribassi fatti a chi paga puntualmente, le proroghe concedute a chi fa nuovi acquisti, le provvigioni esorbitante concedute alle guide di piazza, le informazioni comunicate ai propri corrispondenti, i grossi campioni donati ai sensali, l'invio delle merci alla casa del compratore"), actos todos caracterizados por su condición graciosa (“doni", "ribassi", “campioni donati”) y su vocación de amistad ("proroghe", “informazioni”). Y si el empresario tuviese el hábito "di pagare le provvigioni ai commesi invecchiati al proprio servizio" - los colaboradores más próximos y antiguos de su casa de comercio - se trataría de "usanze continuate per semplice favore" que nunca podemos construir como prestación exigible en derecho (p. 47).

Tampoco lo fueron los auxilios de Manuel Rivero a la flota francesa malparada en Lagos, pero sabemos que "en ocasiones de honra es menester portarnos con las garbosidades precisas". Ni los doblones de Lantery para el entierro de un colega empobrecido; al menos, el saboyano comprendía que "cuando el mundo no me lo pague, Dios me lo pagará a su tiempo". Y de prórrogas y otras concesiones ya nos hablaron 
nuestros polvorientos tratados para huir de pleitos y honrar comerciantes y letras - los Malynes, Peri, Defoe, Savary y compañía. Eran textos que condensaban una práctica de escritorio donde siempre estaba recomendado (y aun se exigía, tratándose de un perfecto negociante) corresponder con fidelidad e informaciones a los amigos y colegas del comercio. Aceptando como tales a los comisionistas, sobre todo a los factores cuando éstos habían "envejecido al propio servicio" (Vivante), el mercader estaba a un paso de concluir con ellos un contrato que uniría sus vidas y haciendas... "como si fueran hermanos". Con el Trattato de Cesare Vivante a la mano, "queste usanze continuate per semplice favore dipendono del beneplacito di chi le osserva".

Seguramente así es. Seguramente, más seguramente todavía, así no fue. 